\title{
Exchange rate dynamics: A nonlinear survey
}

Frank H. Westerhoff

University of Bamberg

Department of Economics

Feldkirchenstraße 21

D-96045 Bamberg

Germany

frank.westerhoff@uni-bamberg.de

\begin{abstract}
According to the chartist-fundamentalist approach, exchange rate fluctuations are at least partially driven by the interactions of heterogeneous boundedly rational speculators who use different trading strategies to determine their orders. This framework is guided by the observation that professional foreign exchange market participants indeed rely on both technical and fundamental analysis rules. Our goal is to survey such models and discuss some key mechanisms which may produce endogenous complex exchange rate dynamics.
\end{abstract}

\section{Keywords}

Foreign exchange markets; Bounded rationality; Technical and fundamental trading rules; Nonlinear dynamics; Stylized facts; Simulation analysis. 


\section{Introduction}

The foreign exchange market is the broadest and most active financial market in the world. Trading volume is enormous. According to the Bank for International Settlement (2005), the global turnover in traditional foreign exchange market segments reached an estimated daily average of US \$ 1.9 trillion in April 2004. Such a high trading volume clearly dwarfs that of other (financial) markets. The nature of foreign exchange markets seems to be highly speculative. The overwhelming part of the trading volume reflects very short-term transactions. For example, operations of intraday traders account for about 75 percent of the market volume. Moreover, international trade transactions represent only a small fraction of the total volume. Speculative transactions are roughly 20 times higher than the sum of world trade and international portfolio investment. Not surprisingly, the fast and hectic trading is also reflected in the dynamics of exchange rates. Foreign exchange markets are characterized by a very high volatility. For instance, the DEM/USD exchange rate changed by about a half percent per day between 1974 and 1998. Even more important, the distribution of the returns displays fat tails. Extreme price changes, say above three percent, appear much more frequently than predicted by the normal distribution.

Is such evidence in line with the efficient market hypothesis? The efficient market hypothesis states that prices always reflect their fundamental values. Hence, price changes are due to unexpected fundamental shocks. Clearly, if we observe an exchange rate movement by five percent, then this should correspond to a five percent shock in the fundamentals. Given also the fact that exchange rates change on a second-to-second basis, it is difficult to imagine where all these fundamental shocks should come from. Note also that other stylized facts such as volatility clustering must also be caused by the news arrival process. All in all, this perspective appears not very convincing and consequently new approaches to model the behavior of exchange rates have emerged. 
Our goal is to provide an elementary introduction to and a survey of the so-called chartist-fundamentalist approach, which may be regarded as a promising part of the currently burgeoning field of behavioral finance (see, e.g. Hirshleifer 2001, Shiller 2003, or Lo 2004). The chartist-fundamentalist approach has strong empirical roots, since it takes into account the observation that professional foreign exchange market participants rely on both technical and fundamental trading strategies when determining their speculative investment positions. Technical analysis aims at identifying trading strategies out of past price movements. Since technical analysis typically suggests going with the current price trend, these trading rules are likely to add a positive feedback to the dynamics. Fundamental analysis bets on a reduction of the mispricing in the market. For instance, when the exchange rate is below its fundamental value, then fundamental analysis suggests buying the undervalued currency. In general, fundamental trading rules add a negative feedback to the dynamics.

A central insight of the chartist-fundamentalist approach is that nonlinear deterministic interactions between positive and negative feedback rules may create complex endogenous dynamics and thus contribute to the turbulent behavior of foreign exchange markets. For recent general reviews of such models see Hommes (2006), LeBaron (2006) or Lux (2006). Moreover, if one adds random shocks to these models, then at least some of them have the potential to replicate certain statistical features of actual exchange rate fluctuations quite well. Put differently, simulated and actual exchange rate time series share the same statistical properties and it is quite hard to tell whether a time series is real or whether it is artificial. Overall, these models may improve our understanding of what is going on in foreign exchange markets. Although still in the beginning stage, this research area may also be useful to design more efficient trading environments and help us to evaluate the effectiveness of certain regulatory mechanisms. 
To obtain a preliminary taste of the models discussed here, let us take a quick glance at the dynamics such models may produce. Suppose that a market is dominated by destabilizing technical traders. Then it is likely that the exchange rate will be driven away from its long-run equilibrium value. This process may continue for some time since technical analysis is likely to be profitable. But the more the exchange rate deviates from its fundamental value, the more traders will realize that a fundamental price correction must eventually set in. At least some traders may therefore abandon technical analysis and opt for fundamental analysis. And in fact, if sufficient traders employ fundamental analysis, the exchange rate will revert towards its long-run equilibrium value. But this may not necessarily be the end of the story. When the misalignment has vanished, potential gains from fundamental analysis appear weak. Speculators may therefore switch back to technical analysis and kick off the next temporary bubble. We will see that such patterns may repeat themselves over and over again, yet in an intricate way. It is worthwhile stressing that the dynamics may emerge completely endogenously, i.e. it is not necessary to assume repeated exogenous shifts in fundamentals. All trading signals needed to keep the process going are generated by the traders themselves.

The remainder is organized as follows: In section 2, we briefly review some important stylized facts of exchange rate dynamics. In section 3, we investigate the trading behavior of professional foreign exchange market participants and also sketch the essence of technical and fundamental analysis. In section 4, we explore several nonlinear deterministic models with interacting chartists and fundamentalists that have the power to produce endogenous complex dynamics. In section 5, we show that if such models are buffeted with dynamic noise, quite realistic exchange rate dynamics may be generated. In section 6, we debate some policy issues and discuss some open problems and potential avenues for future research. The last section concludes the paper. 


\section{Some stylized facts}

In recent years, it has become clear that the price statistics across a wide range of quite different speculative markets exhibit certain universal properties. For in-depth accounts of these stylized facts see, e.g. Guillaume et al. (1997), Mantenga and Stanley (2000), Cont (2001), Lux and Ausloos (2002), Johnson, Jefferies and Hui (2003) or Sornette (2003). We will focus on the following five features:

- Foreign exchange markets regularly produce significant bubbles and crashes. If exchange rates always reflected their fundamental values, crashes ought to correspond to really bad shocks. However, thorough ex-post analyses of crashes are in many cases inconclusive as to what this dramatic piece of new information might have been. Empirical studies suggest that many crashes occur endogenously due to market instabilities.

- Exchange rate volatility is too high to be justified by fundamental shocks. As just mentioned, distinct changes in exchange rates often appear to be unrelated to the arrival of significant new information. Excess volatility is also reflected in the fact that exchange rates typically move on a second-to-second basis whereas news hits the market less frequently.

- The distribution of the returns deviates significantly from the normal distribution and possesses fat tails. Fat-tailedness may be quantified by estimating the so-called tail index. For many different exchange rates, the tail index hovers between 3 and 4, implying that the fourth moment of the distribution of the returns (i.e. the kurtosis) does not exist.

- Exchange rate increments are uncorrelated. For instance, the autocorrelation function of raw returns is essentially zero for all time lags. As a result, the evolution of exchange rates resembles a random walk.

- Periods of low volatility alternate with periods of high volatility. The autocorrelation function for absolute returns is positive and decays slowly. Temporal correlation in volatility may last several months. 
Figures 1 and 2 seek to illustrate these properties for DEM/USD and JPY/USD exchange rates, respectively. The time window ranges from 1974 and 1998, so that we have 6264 daily observations for each time series. The first panels present the exchange rates in the time domain. One of the most popular examples of a bubble-and-crash pattern is given by the path of the DEM/USD exchange rate in the 1980s. Over the period 1981-1984, when real interest rates in the United States rose above those among trading partners, the dollar appreciated from DM 1.93 to DM 2.67. At times, however, the path of the dollar departed from what would be expected on the basis of macroeconomic fundamentals. The most dramatic episode is the period from June 1984 to February 1985. The dollar appreciated further from DM 2.67 to DM 3.46 over this interval, even though the real interest differential had already begun to fall. Other observable factors at that time were also moving in the wrong direction to explain the dollar rise. Taking these observations into account, one may argue that a substantial fraction of the appreciation was due to nonfundamental forces. After February 1985, the bubble burst. By the end of 1987, the exchange rate dropped below DM 1.60.

---------- Figures 1 and 2 go about here

The second panels of figures 1 and 2 show the evolution of the returns, i.e. the changes in log exchange rates. Note that extreme returns may be as large as 5 percent. Between October 6-8, 1998, the JPY/USD exchange rate even made a spectacular cumulative jump of about 14 percent. A common proxy for volatility is given by the average absolute return, which is about 0.5 percent per time step for the two time series. Although we do not have exact knowledge of the variability of the fundamentals, such volatility estimates appear to be too high to be justified solely by fundamental shocks. In addition, at least some of the more distinct exchange rate changes appear to be unrelated to any new information.

The third lines of panels of figures 1 and 2 depict the distributions of the returns. The dotted lines indicate the corresponding normal distributions, represented by identical mean 
and variance. The left-hand panels contain the plain histograms of the returns. Note that the shapes of the distributions appear well behaved: The histograms are unimodal, almost symmetric and bell-shaped. The right-hand panels contain log-linear plots of the distribution of the normalized returns. The returns are normalized by dividing by the standard deviation. The right-hand panels clearly show that extreme returns occur more frequently than warranted by the normal distribution. Overall, we may conclude that the distributions of exchange rate returns are more concentrated around the mean, have thinner shoulders and possess more probability mass in the tails.

The bottom two panels of figures 1 and 2 display the autocorrelation function of raw returns and of absolute returns, respectively. The dotted lines indicate 95 percent confidence bands. Note that for almost all lags, the autocorrelation of raw returns is not significant. Hence, the evolution of exchange rates is close to a random walk. A different picture emerges when one explores the autocorrelation function of absolute returns. The autocorrelation coefficients for the first 100 lags are positive and significant, clear evidence of volatility clustering.

\section{Trader behavior}

Since Simon (1955), a considerable amount of empirical evidence has been collected which impressively demonstrates that people generally lack the computational power to derive fully optimal actions. But this does not imply that they are completely irrational. In fact, people strive to do the right thing. Their behavior may better be described as rule-governed behavior. As argued by psychologists Kahneman, Slovic and Tversky (1986), people tend to follow simple heuristics which have proven to be useful in the recent past. Natural selection pressure apparently limits the number of applied rules. If a certain strategy repeatedly fails to satisfy people, they will, of course, stop using it. Note that this may be an important observation: If 
we are able to identify the agents' main heuristics, then we may be able to model and explore their behavior. But how do professional foreign exchange traders behave in reality? Fortunately, empirical studies give us a quite clear description of their activity.

Due to Smith (1991), who pioneered the use of laboratory financial market experiments, we are nowadays able to observe investor behavior in a well-defined and controlled environment. In such experiments, each participant typically receives an initial portfolio of cash and assets and is free to trade. Trading is conducted by computer through local networks and thus mimics trading in real financial markets quite well. When all participants have entered their action, the next period's price is revealed. The experiments indicate that the participants use simple forms of forecast rules such as (destabilizing) extrapolative or (stabilizing) regressive predictors. Furthermore, they frequently drove prices far above fundamentals, after which the markets crashed. Bubble-and-crash sequences appear to be quite robust, even when all agents know the true fundamental value of the market (Caginalp, Porter and Smith 2001, Sonnemans et al. 2003). Hommes et al. (2005), who have particularly designed their experiments to study the agents' expectation formation process, find that agents tend to coordinate on some popular prediction strategies. Such coordination behavior furthermore suggests that the number of applied financial trading rules may be rather limited, at least at certain times.

Laboratory experiments are typically conducted with students. A related strand of literature explores the behavior of professional market participants who have repeatedly been asked over an extended period of time to forecast the course of exchange rates for different time horizons (e.g. Frankel and Froot 1987, Ito, 1990, Takagi 1991). These studies report that expectations of foreign exchange market participants are not rational. Instead, standard models such as extrapolative or regressive expectation formation models obtain significant empirical support (which is in agreement with the laboratory results mentioned above). 
Interestingly, short-term expectations are quite different from long-term expectations. Destabilizing bandwagon expectations dominate on short-term horizons: When there is an exchange rate trend, it is then believed that this trend will continue. On long-term horizons, expectations tend to be stabilizing. For instance, the respondents predicted reversals of exchange rate trends or adjustments towards long-run equilibrium values.

Finally, professional market participants have also been directly asked how they form their prediction. As reported by Taylor and Allen (1992), Menkhoff (1997) and Lui and Mole (1998), professional foreign exchange market participants rely on both technical and fundamental analysis when they determine their orders. Most professional traders are familiar with both concepts. With respect to long-term horizons, the vast majority of respondents prefer fundamental analysis as a prediction instrument. However, foreign exchange markets are dominated by short-term transactions. For short-term horizons, say up to one week, technical and fundamental analysis are judged as equally important. Which rule is applied in a given situation seems to depend on market circumstances.

Let us briefly sketch the key elements of these trading strategies. Fundamental analysis is the study of economic and political conditions in an effort to determine the intrinsic (fundamental) value of a currency. A typical benchmark for the fundamental value might be derived from the purchasing power parity condition or more elaborate structural macroeconomic models. A fundamentalist believes that an exchange rate may deviate from its intrinsic value in the short run, but converges to it in the long run. Thus the idea is to buy undervalued currencies and to sell overvalued currencies in the hope of a future price correction. From an economist's point of view, such behavior - which is basically equivalent to forming regressive expectations - appears to be reasonable.

Rather than attempting to compute intrinsic values, chartists instead look for price patterns that may indicate the future direction of exchange rates. Standard manuals of 
technical analysis include Edwards and Magee (1966), Pring (1991) and Murphy (1999). Technical analysis is a prediction method founded in the belief that current prices represent all necessary information about an asset. Studying price action is thus all that is required. The most basic concept of technical analysis is that markets have a tendency to follow trends, hence the saying "the trend is your friend”. In general, technical trading rules suggest buying when prices increase, and vice versa. Positive feedback trading obviously corresponds to forming extrapolative expectations.

Many economists are skeptical of the usefulness of technical analysis, yet empirical work indicates that at least some technical analysis rules have been profitable in the past (Brock et al. 1992, LeBaron 1999, Lo et al. 2000). The profitability of technical analysis is an interesting issue. What is more important, however, is the observation that many professional traders are indeed using these strategies. And since they influence the evolution of exchange rates, we should try to understand their impact on the price formation process.

\section{Deterministic models}

The last section has revealed that speculators rely on simple technical and fundamental trading rules to determine their orders. The goal of this section is to explore what happens when these trader types clash together in foreign exchange markets. In section 4.1, we start for pedagogical reasons with a linear exchange rate model. In the following subsections, we then investigate various nonlinear mechanisms that may stimulate endogenous dynamics.

\subsection{A simple linear model}

We develop a simple exchange rate model with chartists and fundamentalists. Since its law of motion is given by a two-dimensional linear difference equation, the dynamics of the model is easy to characterize. The price adjustment process is modeled according to a so-called price 
impact function. A price impact function relates the amount of foreign currency bought or sold in a given time interval to the price change caused by these orders. One may therefore express the log of the exchange rate $P$ in period $t+1$ as

$P_{t+1}=P_{t}+A_{t}\left(W_{t}^{C} D_{t}^{C}+W_{t}^{F} D_{t}^{F}\right)$

where $A$ captures the (positive) price adjustment speed with respect to the excess demand, ${ }^{C}$ stands for the fraction of chartists, $W^{F}$ denotes the fraction of fundamentalists, $D^{C}$ are the orders generated by technical trading rules, and $D^{F}$ are the orders generated by fundamental trading rules. Note that when excess demand is positive (negative), the exchange rate increases (decreases).

Technical analysis rules extrapolate past price trends. Orders triggered by technical trading rules may be formalized as

$D_{t}^{C}=b\left(P_{t}-P_{t-1}\right)$

where $b$ is a positive reaction parameter. A buying signal is given when the exchange rate increases and a selling signal is given when it decreases.

Fundamental analysis aims at exploiting the mispricing in the market. Orders generated by fundamental trading rules may be written as

$D_{t}^{F}=c\left(F-P_{t}\right)$,

where $c$ is a positive reaction parameter and $F$ represents the log of the fundamental value. When the exchange rate is below (above) its fundamental value, buying (selling) is suggested.

For $A_{t}=a, W_{t}^{C}=W^{C}$ and $W_{t}^{F}=W^{F}$ the law of motion of the exchange rate is a two-dimensional linear difference equation

$P_{t+1}+\left(a c W^{F}-a b W^{C}-1\right) P_{t}+a b W^{C} P_{t-1}=a c W^{F} F$.

Rewriting Schur's stability conditions shows us that the unique fixed point $P=F$ is stable if 
(i) $a c W^{F}>0$, (ii) $a c W^{F}<2+2 a b W^{C}$ and (iii) $a b W^{C}<1$. Since all parameters are by definition positive, condition (i) is always fulfilled, yet conditions (ii) and (iii) impose true restrictions. Stability may be lost when either the total market impact of the fundamentalists (given by $a c W^{F}$ ) or the total market impact of the chartists (given by $a b W^{C}$ ) exceeds a certain critical threshold. Note also that condition (ii) implies that in the presence of some chartists $\left(0<a b W^{C}<1\right)$, the stability requirement for the fundamentalists is less strict than when there are no chartists. In this sense, a positive but not too high fraction of chartists may be beneficial for market stability.

Figure 3 shows a simulation run for $a=1, b=1.5, c=2, F=1, W^{C}=W^{F}=0.5$ and an initial exchange rate shock of 1 percent. In an efficient market, the exchange rate would jump back towards its fundamental value in the next period without any transactions. But this does not happen in our case: The first panel reveals that the exchange rate fluctuates with a decreasing amplitude around its fundamental value. The bottom two panels display the corresponding orders of the chartists and fundamentalists, respectively. Depending on the resulting excess demand, the exchange rate may go up or down. After about 25 periods, the dynamics has more or less died out. Within linear models, a single impulse may only trigger temporary exchange rate movements. This, however, already contributes to the excessive behavior of exchange rates and also to the high trading volume, as observed in real markets.

Figures 3 goes about here

\subsection{Nonlinear price impact function}

In the previous section, we applied a log-linear price impact function. One might imagine that such a function is a general description of a more complex limit order book mechanism (see, e.g. Chiarella and Iori 2002 for such a modeling approach) or reflects a stylized representation 
of the behavior of market makers. The market maker scenario is a popular and also realistic description of the actual price adjustment in foreign exchange markets (see Lyons 2001 for an empirical account). Market makers are large market participants who stand ready to absorb imbalances between buyers and sellers. They supply excess demand from their inventory or accumulate inventory when there is an excess supply. Market makers adjust prices by paying attention to two kinds of information. On the one hand, they react to excess demand. When excess demand is positive (negative), prices go up (down). On the other hand, they closely watch their inventory. Market makers dislike large inventory imbalances and thus may quote prices that help to unwind their positions. While the first aspect is captured by the price impact function, the second aspect is often neglected. One exception is Westerhoff (2003a), who develops a simple exchange rate model in which the market makers control their positions by quoting exchange rates that provoke offsetting orders of technical and fundamental traders. Such behavior may amplify trading volume and exchange rate variability. Similar results are reported by Gu (1995), who argues that market makers have an incentive to churn the market in order to raise profits.

The price impact function may also be nonlinear for another important reason. Trading volume in foreign exchange markets is not constant over time. According to the Bank for International Settlement (2005), which estimates the trading volume in foreign exchange markets every three years, average daily turnover dropped from US \$ 1.6 trillion in April 1998 to US \$ 1.4 trillion in April 2001. In April 2004, however, average daily trading volume was recorded at a record high of US \$ 1.9 trillion. The price adjustment may thus also depend on market depth: A given transaction may cause a larger price change when market depth is low than when it is high. In this section, we focus on this aspect. We will see that even slight variations in the price adjustment speed may lead to endogenous exchange rate motion.

To be precise, the price adjustment is now modeled as 
$P_{t+1}=P_{t}+A_{t}\left(W_{t}^{C} D_{t}^{C}+W_{t}^{F} D_{t}^{F}\right)$,

with

$A_{t}=\left\{\begin{array}{ll}x & \text { for } \quad\left|W_{t}^{C} D_{t}^{C}\right|+\left|W_{t}^{F} D_{t}^{F}\right|>z \\ y & \text { otherwise }\end{array}\right.$.

Depending on whether trading volume is above or below a certain threshold level $z$, the price adjustment speed is high or low, i.e. $0<x<y$. Westerhoff (2004a) discusses the case in which the price adjustment function is smooth with respect to liquidity.

The remainder of the model is as in the previous section. The weights of chartists and fundamentalists are fixed. Chartists extrapolate past price trends

$D_{t}^{C}=b\left(P_{t}-P_{t-1}\right)$,

while fundamentalists bet on mean reversion

$D_{t}^{F}=c\left(F-P_{t}\right)$

The reaction coefficients $b$ and $c$ are positive and the fundamental value is constant.

Figure 4 presents a simulation run of the model for $x=1.33, y=1.35$ and $z=0.01$.

As before, we set $b=1.5, c=2, F=1$ and $W^{C}=W^{F}=0.5$. The only difference between the two simulation runs is thus given by the price adjustment speed. Note that in the linear model market stability requires that $a<1 . \overline{3}$, which is in between the assumed values for $x$ and $y$. The panels of figure 2 show from top to bottom the evolution of the log of the exchange rate, the orders of the chartists, the orders of the fundamentalists, and the price adjustment speed, respectively. Visual inspection reveals that the exchange rate does not settle down at its fixed point but continuously moves up or down.

Figures 4 goes about here

What is driving the dynamics of the model? Note that the market switches back and 
forth between two regimes. When liquidity is high, the market is stable and price fluctuations decline. But low price fluctuations indicate only weak trading signals and thus the transactions of the speculators decrease. As liquidity decreases, however, the price responsiveness of a given trade increases. The market therefore becomes unstable and price fluctuations increase again. Consequently, traders perceive stronger trading signals and trading volume goes up. When trading volume exceeds a critical value, the price responsiveness of a given trade decreases again. Although differences in $x$ and $y$ are quite small, everlasting exchange rate fluctuations are the result.

\subsection{Nonlinear trading rules}

One major reason for endogenous complex foreign exchange dynamics may be that the trading rules of the market participants are nonlinear. In fact, there are numerous nonlinear technical trading rules. Prominent examples include head-and-shoulders patterns or filter rules. Nonlinear technical trading has been explored by, e.g. Chiarella (1992), Farmer (2002), Farmer and Joshi (2002), Chiarella, Dieci and Gardini (2002) and Westerhoff (2006). But fundamental trading rules may also be nonlinear. A famous model which considers this aspect is Day and Huang (1990). Variations of this theme are discussed in Huang and Day (2003) and He and Westerhoff (2005). The goal of this subsection is to illustrate the dynamics of such models. We focus on nonlinear fundamental trading rules.

\subsubsection{A nonlinear fundamental trading rule}

We assume a log-linear price impact function. The exchange rate for period $t+1$ is given as

$$
P_{t+1}=P_{t}+a\left(W^{C} D_{t}^{C}+W^{F} D_{t}^{F}\right)
$$

The price adjustment speed and the fractions of the chartists and the fundamentalists are 
fixed. The chartists again use a linear trading rule and extrapolate past price trends

$D_{t}^{C}=b\left(P_{t}-P_{t-1}\right)$,

where $b$ is a positive reaction coefficient.

The fundamentalists use a nonlinear trading rule. Their orders are determined by

$D_{t}^{F}=c\left(F-P_{t}\right) \sqrt{\left|F-P_{t}\right|}$.

Since the reaction coefficient $c$ is positive, fundamentalists buy when the exchange rate is below its fundamental value and sell when the exchange rate is above its fundamental value. Due to the square root expression, the strength of trading activity is time-dependent: The larger the misalignment in the market, the higher the confidence of the fundamentalists in the usefulness of their trading strategy, and thus their activity level increases. Such changes in confidence may be justified by the fact that profit opportunities of fundamental trading rules increase with the misalignment (Day and Huang 1990).

Note again that all other aspects are as in our linear benchmark model. How does the nonlinear fundamental trading rule influence the dynamics of our model? Figure 5 presents a simulation run for $a=1, b=2, c=38, F=1, W^{C}=W^{F}=0.5$ and an initial exchange rate shock of 1 percent. The panels display from top to bottom the log of the exchange rate, the demand of the chartists and the demand of the fundamentalists, respectively. Visual inspection reveals that the exchange rate fluctuates around its fundamental value without any apparent tendency to converge.

Figures 5 goes about here

The story of the dynamics is quite easy to grasp. When the exchange rate is far away from its fundamental value, the fundamentalists are quite confident of their trading strategy and trade rather aggressively. Their orders dominate those of the chartists and drive the exchange rate back towards fundamentals. However, when the exchange rate is close to 
fundamentals, fundamental analysis is not regarded as very attractive and thus its market impact is relatively weak. In this situation the market is governed by the destabilizing orders of the chartists, who create the next temporary bubbles. The process then repeats itself.

\subsubsection{Variation 1: Emergence of bull and bear markets}

One might argue that the behavior of the exchange rate depicted in figure 5 does not look very spectacular. However, this may change when we modify the behavior of the chartists. As in Day and Huang (1990), we now assume that the chartists either believe in the persistence of bull or bear markets. Their orders are now approximated by

$D_{t}^{C}=b\left(P_{t}-F\right)$,

where $b$ is a positive reaction coefficient. Accordingly, the chartists submit buying orders when the market is overvalued, in the belief that the market will further increase. In a bear market, the chartists are pessimistic and submit selling orders to the market.

Figure 6 shows a simulation run for $a=1, b=12, c=18, F=1, W^{C}=W^{F}=0.5$. From top to bottom we see the evolution of the log of the exchange rate, the orders of the chartists and the orders of the fundamentalists, respectively. Now the dynamics looks spectacular! We observe the emergence of bull and bear markets, intricate switching between bull and bear markets and irregular motion within bull or bear markets.

--------- Figures 6 goes about here

The dynamics of the model may be sketched as follows. Suppose that the exchange rate is slightly above its fundamental value. Then chartists dominate the market and drive the exchange rate up. However, the larger the mispricing, the stronger the trading activity of the fundamentalists. At some point in time they are stronger than the chartists and push the exchange rate back towards fundamentals. But then the chartists are back in charge and the 
exchange rate increases again. This explains the apparent random evolution of the exchange rate in the bull market. The same story holds, of course, in the bear market. What causes a shift from a bull to a bear or a bear to a bull market? Suppose that the exchange rate is extremely high. Then the chartists are still buying but the fundamentalists are selling strongly. Their selling pressure may not only drive the exchange rate down but may cause a severe crash in which the exchange rate is pushed below its fundamental value. Then a bull market turns into a bear market.

\subsubsection{Variation 2: Decreasing impact of fundamental analysis}

In the previous two models we have assumed that the confidence of the fundamentalists in their trading rules increases as the distance between the exchange rate and its fundamental value grows. The motivation was that profit opportunities increase with the misalignment. But one should note that as long as the exchange rate runs away from its fundamental value, the fundamentalists mispredict the direction of the exchange rate and their trading strategies are highly unprofitable. One might therefore also assume that the fundamentalists lose confidence in fundamental analysis in such a situation. Let us briefly explore what may happen then. We use the same model as in section 4.3.1 but now assume that the orders of the fundamentalists are determined by

$D_{t}^{F}=c\left(F-P_{t}\right) / \sqrt{d+\left|F-P_{t}\right|}$.

Since parameters $c$ and $d$ are positive, the fundamentalists are still betting on a reduction of the mispricing, yet their aggressiveness decreases with the misalignment.

Figure 7 illustrates the dynamics for $a=1, b=2, c=2.4, d=0.001, F=1$ and $W^{C}=W^{F}=0.5$. The nonlinear interactions between the chartists and the fundamentalists again create a complex development of the exchange rate. Remember from section 4.1 that 
the fundamentalists may also be a source of market instability when they trade too aggressively. This is here the case close to the fundamental value. The size of the orders of the fundamentalists is so strong that it causes an overshooting of the exchange rate. Fortunately, their market impact weakens when the exchange rate disconnects from fundamentals such that the market does not explode. The role of the chartists is that they contribute to the turbulence. If their behavior is excluded, more regular motion sets in.

\section{Figures 7 goes about here}

Is such a scenario completely out of the blue? Westerhoff and Reitz present (2003) empirical evidence that the market impact of the fundamentalists may indeed decrease with the misalignment. A similar theoretical argument is made by Frankel and Froot $(1986,1990)$, who claim that fundamental analysis will be used less forcefully when the exchange rate traces out a bubble path. This brings us to the next section in which we discuss models where agents may select their trading strategies.

\subsection{Endogenous selection of trading strategies}

In the majority of models, the fraction of chartists and fundamentalists is determined endogenously. Quite different mechanisms have been proposed. Frankel and Froot (1986, 1990) discuss a model in which a portfolio manager uses a weighted average of the predictions of chartists and fundamentalists. The better a group predicts the course of the exchange rate, the larger its weight becomes. Brock and Hommes $(1997,1998)$ develop a framework in which the fraction of technical and fundamental trading rules depends on their evolutionary fitness: A given strategy gains in popularity when it produces profits. Lux (1995, 1997, 1998) and Lux and Marchesi (2000) present a related mechanism in which the impact of technical and fundamental analysis depends on profit differentials. The goal of this section is to illustrate a few of these interesting ideas. 


\subsubsection{Selection of strategies according to misalignment}

Let us start with a simple model. Suppose that the log of the exchange rate is quoted as

$P_{t+1}=P_{t}+a\left(W_{t}^{C} D_{t}^{C}+W_{t}^{F} D_{t}^{F}\right)$

where $a>0$ captures the price adjustment speed. The fractions of chartists $W_{t}^{C}$ and fundamentalists $W_{t}^{F}$ are now time-dependent. As in our benchmark model, chartists extrapolate the exchange rate trend

$D_{t}^{C}=b\left(P_{t}-P_{t-1}\right)$

while fundamentalists expect a mean reversion

$D_{t}^{F}=c\left(F-P_{t}\right)$

The parameters $b$ and $c$ are positive and the $\log$ of the fundamental value $F$ is constant.

In each period, traders choose between technical and fundamental analysis rules. The traders seek to exploit bull and bear market situations but they are also aware that such behavior is risky. The more the exchange rate deviates from its fundamental value, the more traders come to the conclusion that the bull or bear market might collapse. As a result, an increasing number of them opt for fundamental analysis, which appears superior. The market share of technical traders is defined as

$W_{t}^{C}=\frac{1}{1+e\left(F-P_{t}\right)^{2}}$

Since the market shares add up to one, the weight of the fundamentalists is $W_{t}^{F}=1-W_{t}^{C}$. Note that the higher parameter $e>0$ is, the faster the agents switch to fundamental analysis as the misalignment increases.

A typical simulation run for $a=1, b=9, c=0.2, e=20000$ and $F=1$ is presented in figure 8. The panels show the log of the exchange rate, the demand of the chartists, the 
demand of the fundamentalists, and the fraction of chartists, respectively. As can be seen, the exchange rate circles in a complex manner around its fundamental value. Note that the fraction of chartists varies strongly. When the exchange rate is close to its fundamental value, most traders prefer technical analysis, and the exchange rate is consequently driven away from its fundamental value. However, the weight of the chartists decreases with increasing misalignments. When the majority of traders rely on fundamental analysis, a period of convergence sets in until this process repeats itself.

---------- Figures 8 goes about here

Such switching behavior is, for example, stressed by Hommes (2001). A model along these lines is discussed in Westerhoff (2003b). Similar models are due to de Grauwe and Dewachter (1992, 1993). They also present a very interesting alternative explanation for the above switching model. In their approach, fundamentalists are heterogeneous. They perceive the fundamental value correctly, but only on average. When the exchange rate is equal to its fundamental value, half of the fundamentalists view the exchange rate as overvalued and half as undervalued. As a result, the orders of the fundamentalists cancel out each other. However, when the exchange rate disconnects from its fundamental value, more and more fundamentalists agree on the direction of the future exchange rate path and thus their net impact increases. When the orders of the fundamentalists cancel out each other, the market impact of the chartists is obviously maximal and when all fundamentalists agree on the future direction of the exchange rate, the market impact of chartists is minimal.

Moreover, de Grauwe, Dewachter and Embrechts (1993) demonstrate that other technical trading rules may easily increase the complexity of the exchange rate process. They suggest modeling the orders of chartists as

$D_{t}^{C}=b\left(\left(P_{t}-P_{t-1}\right)-0.5\left(P_{t}-P_{t-3}\right)\right)$. 
Accordingly, the chartists rely on what is called a double-crossover method. Such a method combines two moving averages. When a short-term moving average of the past exchange rates crosses a long-term moving average of the past exchange rates from below (above), then a buying (selling) signal is triggered. The strength of trading depends on $b>0$. For simplicity, the short-term moving average is a two-period change and the long-term moving average a three-period change. Higher lag structures may, of course, intensify the dynamics.

Figure 9 shows how such trading behavior modifies the dynamics of the model. The simulation run is generated with $a=1, b=10, c=0.25, e=5000$ and $F=1$. The panels show the log of the exchange rate, the demand of the chartists, the demand of the fundamentalists, and the fraction of chartists, respectively. Compared to figure 8, the dynamics now appears to be much more intricate. The exchange rate may, for instance, remain for some periods above or below its fundamental value. However, the story behind the dynamics is essentially the same.

Figures 9 goes about here

\subsubsection{Selection of strategies according to evolutionary fitness measures}

What investors care most about is profits. It thus seems reasonable to base the agents' choice of trading rules on the rules' past performance. Here we consider a simple example which is closely related to the Brock and Hommes $(1997,1998)$ framework. The log of the exchange rate in time step $t+1$ is announced as

$P_{t+1}=P_{t}+a\left(W_{t}^{C} D_{t}^{C}+W_{t}^{F} D_{t}^{F}\right)$,

with

$D_{t}^{C}=b\left(P_{t}-P_{t-1}\right)$

as the orders of technical trading rules and 
$D_{t}^{F}=c\left(F-P_{t}\right)$

as the orders of fundamental trading rules. Parameters $a, b$ and $c$ are again positive and the fundamentals are constant.

The impact of a trading strategy depends on its evolutionary fitness. The fitness of technical analysis is defined as

$K_{t}^{C}=\left(\operatorname{Exp}\left[P_{t}\right]-\operatorname{Exp}\left[P_{t-1}\right]\right) D_{t-2}^{C}$,

while the fitness of fundamental analysis is given as

$K_{t}^{F}=\left(\operatorname{Exp}\left[P_{t}\right]-\operatorname{Exp}\left[P_{t-1}\right]\right) D_{t-2}^{F} \cdot$

Obviously, the fitness of the trading strategies depends on their most recent performance. The time structure of the model is as follows. Orders submitted in period $t-2$ are filled at prices in period $t-1$. Whether or not a transaction will produce a (myopic) profit then depends on the realized price in period $t$. One may further consider that the agents do not forget the fitness values of past trading periods, i.e. that they possess a memory.

The higher the fitness of a strategy, the more agents will rely on it. The fraction of agents deciding on technical analysis is

$$
W_{t}^{C}=\frac{\operatorname{Exp}\left[g K_{t}^{C}\right]}{\operatorname{Exp}\left[g K_{t}^{C}\right]+\operatorname{Exp}\left[g K_{t}^{F}\right]} .
$$

The fraction of agents selecting fundamental analysis is

$$
W_{t}^{F}=\frac{\operatorname{Exp}\left[g K_{t}^{F}\right]}{\operatorname{Exp}\left[g K_{t}^{C}\right]+\operatorname{Exp}\left[g K_{t}^{F}\right]} .
$$

The parameter $g>0$ captures how sensitive the mass of agents is to select the most attractive strategy. The higher $g$ is, the more agents will select the strategy with the highest fitness. In this sense, $g$ may also be interpreted as a rationality parameter. 
The dynamics of the model are depicted in figure 10, where we assume that $a=1$, $b=2.9, c=1.225, g=150$ and $F=1$. We see from top to bottom the log of the exchange rate, the demand of the chartists, the demand of the fundamentalists, and the fraction of chartists, respectively. A permanent evolutionary competition between the trading rules causes endogenous exchange rate dynamics.

--------- Figures 10 goes about here

In a stylized way, the dynamics evolves as follows. During an exchange rate trend, technical analysis is profitable. However, technical analysis produces strong forecast errors at turning points. When the exchange rate reverts towards its fundamental value, fundamental analysis becomes profitable. The profitability of technical and fundamental analysis continously varies as the exchange rate oscillates around its fundamental value. Hence, the dynamics may not die out but continue.

\subsection{Interactions between markets}

Until now, speculators have been active in one market only. In reality, however, speculators may wander around markets. This aspect has only recently received attention. It should be obvious that if traders can switch between markets, this may lead to intricate dynamics since the composition of technical and fundamental traders on a market may change over time. First setups in this direction have been suggested by Westerhoff (2004b), Chiarella, Dieci and Gardini (2005), and Westerhoff and Dieci (2006).

Here we discuss the approach of Westerhoff and Wieland (2004) who consider $h=1,2, \ldots, H$ foreign exchange markets in their model. Fundamentalists are regarded as experts who specialize in one market and thus remain in that market. Since chartists use rather flexible trading rules, they may easily switch between markets. The chartists seek to exploit price trends but strongly dislike misaligned markets. The log of the exchange rate in market $h$ 
at time step $t+1$ is quoted as

$P_{t+1}^{h}=P_{t}^{h}+a^{h}\left(W_{t}^{C, h} D_{t}^{C, h}+D_{t}^{F, h}\right)$.

The orders of technical trading rules in market $h$ depend on the observed exchange rate trend $D_{t}^{C, h}=b^{h}\left(P_{t}^{h}-P_{t-1}^{h}\right)$.

The orders of the fundamental trading rules in market $h$ increase with the mispricing

$D_{t}^{F, h}=c^{h}\left(F^{h}-P_{t}^{h}\right)$.

Parameters $a^{h}, b^{h}$ and $c^{h}$ are all positive.

The chartists seek to profit from exchange rate trends. But, as is well known, eventually every bubble bursts. Chartists identify the risk of being caught in a bursting bubble as

$$
K_{t}^{h}=\log \frac{1}{1+j^{h}\left(F^{h}-P_{t}^{h}\right)^{2}} .
$$

This fitness function is bell-shaped and bounded between minus infinity and zero. Note that the larger the distance between the exchange rate and its fundamental value, the lower the fitness of a market. How quickly the fitness of a market changes depends on $j^{h}>0$.

The fraction of chartists entering market $h$ is determined by

$$
W_{t}^{C, h}=\frac{\operatorname{Exp}\left[g^{h} K_{t}^{h}\right]}{\sum_{h=1}^{H} \operatorname{Exp}\left[g^{h} K_{t}^{h}\right]} .
$$

The higher the attractiveness of a market, the more chartists will enter that market. Parameter $g^{h}$ may again be regarded as a rationality parameter since it captures how sensitive the mass of traders is to select the most attractive market.

All $h$ markets involve the same key currency (say the US dollar). Implicitly, the 
model fixes several cross rates. Figure 11 displays a simulation run for $H=5$ symmetric markets and $a=1, b=5, c=0.2, g=1.2, j=500000$ and $F=1$. The panels show from top to bottom the log of the exchange rate in market 1 , the log of the exchange rate in market 2 , and the log of the cross rate between markets 1 and 2, respectively.

---------- Figures 11 goes about here

The exchange rates in markets 1 and 2 and also the cross rates fluctuate around their fundamental values in a complex manner. For some periods, the markets are relatively stable. At other times, volatility is elevated. When elevated, all markets usually display strong exchange rate fluctuations. What is going on here? Suppose that a market is dominated by chartists. Then it is likely that the exchange rate is driven away from its fundamental value. However, this decreases the fitness of the market for the chartist. The chartists leave the market (they enter another market which will then be destabilized) and thus the fundamentalists drive the exchange rate back to fundamental values. This increases the fitness of the market and the chartists are likely to return soon.

\subsection{Summary and some additional mechanisms}

The goal of section 4 is to illustrate some important nonlinear mechanisms that may contribute to the complex behavior of exchange rates. From these examples it should have become clear by now that nonlinear motion is rather the rule than the exception. Let us mention some other nonlinear approaches. Kaizoji (2002) develops a model in which both technical and fundamental trading rules are nonlinear. Li and Rosser (2001, 2004) present a model in which traders may switch between a linear technical trading rule and a nonlinear fundamental trading rule. In Chiarella and He (2001, 2005), the dynamics is further complicated by the fact that the agents' wealth changes over time. When certain trader types become wealthier, they obtain a stronger impact on prices. De Grauwe and Grimaldi (2006, 
2007) focus on the mean reversion pressure that results from the goods markets. Due to transaction costs, mean reversion pressure from the goods markets may be absent. But when it kicks in, fundamentalists may take this into account and trade more aggressively. Last but not least, Rosser, Ahmed and Hartmann (2003) explore what may happen when the evolution of the fundamental value itself is a chaotic process. Clearly, fundamentals are not constant over time but may change with respect to (nonlinear) macroeconomic developments. When traders react to changes in the fundamentals, quite intricate dynamics may arise.

So far we have illustrated the dynamics of the models by plotting them in the time domain. However, part of the models' complexity is better revealed in a phase space representation. The eight panels of figure 12 show the dynamics of the eight nonlinear models discussed so far in phase space, that is, the log of the exchange rate in period $t+1$ is plotted against the log of the exchange rate in period $t$. As can be seen, the models may produce socalled strange attractors which indicate that the underlying dynamics may indeed be chaotic. It should be noted that there exists a large battery of quite sophisticated numerical and analytical tools which allow the investigation of the dynamics of the models in much more detail. The interested reader may consult, for instance, Gandolfo (1985), Puu (1989), Medio (1992) or Rosser (2000).

\footnotetext{
--------- Figures 12 goes about here ----------
}

\section{Stochastic models}

In section 4, we reviewed several prominent mechanisms which may lead to complex foreign exchange dynamics. One important mechanism that is still missing is herding behavior. Herding behavior will be discussed in section 5.1. Another goal of the current section is to show that models with heterogeneous interacting agents which are buffeted with dynamic noise may produce quite realistic exchange rate movements. Although the models discussed in section 4 are able to mimic some stylized facts of exchange rates, the dynamics typically 
contains too much structure. With the help of some exogenous disturbances, however, the stylized facts presented in section 2 might be replicated quite well. In section 5.2 we also comment on more sophisticated agent-based computational models.

\subsection{A simple herding model}

We present a simplified version of Kirman's herding model $(1990,1993)$. A central feature of this model is that the agents' selection of trading rules is due to stochastic social interactions. In fact, market participants regularly talk to each other and this may influence their selection of trading rules. Besides becoming "infected” due to communication, the agent's choice of a trading rule may also change exogenously. We will see that when the majority of market participants rely on technical trading rules, the market displays bubbles and crashes. But when the majority of them opt for fundamental analysis, the market becomes rather stable.

In Kirman’s herding model there are two prevalent views of the world, and each agent holds one of them. View 1 corresponds to being a chartist and view 2 to being a fundamentalist. Overall, there are $N$ agents. Denote by $K_{t}$ the number of agents who hold view 1 in time step $t$. The state of the system may be defined by the number $K_{t}$ of agents holding view 1, i.e. $K_{t} \in\{0,1, \ldots, N\}$. The system evolves as follows: Two individuals meet at random. The first is converted to the second's view with probability $(1-\delta)$. Moreover, there is a small probability $\varepsilon$ that the first will change his opinion independently (e.g. an existing agent is replaced by a new one who does not share the same view). The dynamic evolution of the process is given by 
$K_{t}=K_{t-1}+\left\{\begin{array}{ll}1 & \text { with probability } p_{t-1}^{1} \\ -1 & \text { with probability } p_{t-1}^{2} \\ 0 & \text { with probability } 1-p_{t-1}^{1}-p_{t-1}^{2}\end{array}\right.$,

where

$p_{t-1}^{1}=\left(1-\frac{K_{t-1}}{N}\right)\left(\varepsilon+(1-\delta) \frac{K_{t-1}}{N-1}\right)$

and

$p_{t-1}^{2}=\frac{K_{t-1}}{N}\left(\varepsilon+(1-\delta) \frac{N-K_{t-1}}{N-1}\right)$

With probability $p_{t-1}^{1}, K_{t-1}$ increases by +1 and with probability $p_{t-1}^{2}, K_{t-1}$ changes by -1 . With probability $1-p_{t-1}^{1}-p_{t-1}^{2}, K_{t-1}$ remains constant.

The proportion of the time the system will spend in each state depends on the relative values of $\varepsilon$ and $(1-\delta)$. There are two interesting cases: When the probability of selfconversion is relatively high, and the probability of being converted by another agent is relatively low (e.g. $\varepsilon=0.15,1-\delta=0.7, N=100$ ), the state of the system fluctuates around $K=50$ so that most of the probability mass is located in the center. But when the probability of self-conversion is relatively low and the probability of being converted by another agent is relatively high (e.g. $\varepsilon=0.005,1-\delta=0.99, N=100$ ), the system spends most of the time in the extremes. Then nearly all agents hold the same view for some time, but suddenly the whole crowd may switch to the other view. In neither example does the system converge to any particular state $K$, i.e. none of the states $K \in\{0,1, \ldots, N\}$ is, itself, an equilibrium.

Let us now turn to the exchange rate model. The log of the exchange rate adjusts as

$P_{t+1}=P_{t}+a\left(W_{t}^{C} D_{t}^{C}+W_{t}^{F} D_{t}^{F}\right)$ 
where $a>0$ reflects the price adjustment speed with respect to excess demand. The fractions of agents who use technical analysis is defined as

$W_{t}^{C}=K_{t} / N$

The remaining fraction of agents relies on fundamental analysis

$W_{t}^{F}=\left(N-K_{t}\right) / N$.

The chartists extrapolate the exchange rate trend. Depending on $b>0$, their orders are given as

$D_{t}^{C}=b\left(P_{t}-P_{t-1}\right)+\beta_{t}$

In reality, there exists an ocean of different technical trading rules. To capture part of the variety of technical analysis rules, we add a noise term $\beta$, which is normally distributed with mean zero and constant standard deviation $\sigma^{\beta}$.

The orders of the fundamentalists depend on the expected mean reversion

$D_{t}^{F}=c\left(F-P_{t}\right)+\chi_{t}$.

The reaction parameter $c$ is positive and the log of the fundamental value is denoted by $F$. Again we add a normally distributed noise term with mean zero and constant standard deviation $\sigma^{\chi}$, which may reflect that agents use slightly different fundamental trading rules or commit little errors when determining their investment positions.

The dynamics of the model is illustrated by figure 13 . We set $a=1, b=0.05$, $c=0.02, \sigma^{\beta}=0.017, \sigma^{\chi}=0.004, F=1, \varepsilon=0.005$ and $\delta=0.5$. Moreover, 100 time steps in the herding part of the model correspond to 1 time step in the exchange rate model. The panels show from top to bottom the fraction of chartists, the log of the exchange rate, the returns, the probability density function of the returns, the autocorrelation function of raw returns and the autocorrelation function of absolute returns, respectively. Does the model 
match the stylized facts of financial markets? A comparison of figures 1, 2 and 13 reveals some striking similarities: We find bubbles and crashes, a high exchange rate variability, fat tails for the distribution of the returns, the absence of autocorrelation in raw returns and temporal dependence in volatility.

Figures 13 goes about here

All in all, the simple herding model produces quite realistic dynamics. The reason for this is partially revealed by the top panel of figure 13. Changes in opinion may occur quite quickly. The chartists are typically responsible for high exchange rate volatility and may also create bubbles. But due to random interactions among market participants, the market impact of chartists may abruptly decrease. Fundamentalists then push the exchange rate back to fundamental values and the market becomes less volatile. Switching between the trading rules thus also causes volatility clustering. Since the behavior of the traders is partially noisy, the exchange rate returns are uncorrelated.

\subsection{Artificial foreign exchange markets}

Up to now, we concentrated on relatively simple models in which agents rely on a particular technical and a particular fundamental trading rule. Due to nonlinearities, interesting dynamics may evolve. In reality, agents naturally use a much larger set of trading rules. Socalled agent-based computational models seek to take this into account. To illustrate the philosophy of such models, we briefly address the main features of its most prominent member, namely the Santa Fe approach of Palmer et al. (1994), Arthur et al. (1997) and LeBaron et al. (1999). They propose a theory of price formation based on heterogeneous traders. Each agent at any time possesses a multiplicity of forecast rules and uses those that are both best suited to the current state of the market and have recently proved most reliable. Agents learn by discovering which of their predictors prove best, and by developing new ones 
from time to time.

More specifically, each predictor is a condition-forecast rule that contains both a market condition that may at times be fulfilled by the current state of the market and a forecasting formula for the price of the next period. Each agent holds a given number of individual predictors in mind and uses the most accurate of those that are active. Thus, each agent has the ability to recognize different sets of states of the market. For example, if a headand-shoulders pattern has a high performance, a trader will not use it until he has really detected a head-and-shoulders pattern. If a head-and-shoulders pattern emerges, the forecasting part of the predictor triggers a trading position.

The market price is driven by the trading activity of the agents. Once the market clearing price is revealed, the traders update the accuracy of the active predictors. In addition, the traders continually explore new forecasting rules. That is, from time to time they drop rules that perform badly, and create new ones. Learning takes place in two ways: On a rapid base as agents learn which of their predictors are accurate and worth acting upon, and which should be ignored, and at a slower time scale as nonperforming predictors are discarded and new ones are invented.

The model generates very realistic price dynamics. Stylized facts such as excess volatility, fat tails for the distribution of the returns or volatility clustering are replicated. Another important result is that technical trading rules are not forced to exist but endogenously persist in the market. For instance, technical analysis can emerge if trendfollowing predictors are generated by chance in the population, and if random perturbations activate them and subsequently validate them.

The agent-based computation approach has both advantages and disadvantages. On the one hand, agents are allowed to explore a fairly wide range of possible forecasting rules. In addition, they have flexibility in using and ignoring different pieces of information. On the 
other hand, it is often difficult to pin down causalities acting inside the market. Suppose that a model includes 25 traders, each relying on a set of 100 predictors. Then 2500 different predictors can be used at a given time step. As time proceeds, the traders constantly explore new rules. For alternative setups see, e.g. Raberto et al. (2001) or Chen and Yeh (2001). In Lawrenz and Westerhoff (2001), the traders only follow a set of six time-invariant trading rules. The selection of trading rules is modeled via genetic algorithm learning. Their model still allows the development of an intuitive understanding of what is going on in such market models.

\section{Discussion}

Models with heterogeneous interacting agents have the potential to match the stylized facts of foreign exchange markets quite well. In this sense, they also help us to develop a better understanding of the behavior of exchange rates. Since the models are obviously quite powerful, we may use them as computer laboratories to design better trading environments and to explore the effectiveness of certain regulatory mechanisms. Here we briefly discuss preliminary results concerning the workings of central bank interventions and transaction taxes.

Central banks frequently intervene in foreign exchange markets. Such interventions are motivated by the desire to check short-run trends or to correct longer-term deviations from fundamental values. Accordingly, central banks either trade against the current exchange rate trend and thus counter the behavior of chartists or they trade in the direction of the fundamental value and thus act like fundamentalists. These simple strategies are called leaning against the wind and targeting long-run fundamentals. Although central banks seem to believe in the power of intervention operations, both the theoretical and the empirical literature remain skeptical about their usefulness. Westerhoff and Wieland (2004) explore the 
effectiveness of central bank interventions in a system of linked foreign exchange markets (see section 4.5). They find that central bank interventions may, in principle, be able to stabilize exchange rate fluctuations. However, unexpected spillover effects may also arise. If many destabilizing chartists leave the intervention market, then other markets may display stronger exchange rate fluctuations.

How may transaction taxes influence the stability of foreign exchange markets? Westerhoff and Dieci (2006) develop a model in which agents may trade in two different markets, using both technical or fundamental trading rules. In addition, the agents are free to trade, i.e. they may become inactive. If a central authority imposes a transaction tax in one market only, then the taxed (untaxed) market becomes stabilized (destabilized). The main reason is that some (destabilizing) traders migrate from the taxed market to the untaxed market. If a uniform transaction tax is imposed in both markets, then both markets become less volatile and distorted. The analysis also reveals that technical traders are more punished by a transaction tax than fundamental traders. The profits of technical traders are to some degree random and based on a strong trading intensity.

Let us finally stress some open problems and potential avenues for future research. We have modeled the price adjustment by assuming a fixed relation between excess demand and consecutive price changes. One may interpret this as a stylized description of the activity of market makers. However, a more detailed underpinning would be desirable. For instance, how do market makers adjust prices with respect to their inventory? The fundamental value is typically set at constant or modeled as a simple random walk. It would be very interesting to see how other types of processes of the fundamental value may affect interactions between heterogeneous agents. In addition, we have always assumed that the agents perceive the fundamental value correctly. That is, of course, a rather strong assumption. People may have some knowledge about the fundamental value but are not aware of its true law of motion. A 
theory of how agents perceive fundamentals is missing. A related question is how agents react to the arrival of new information. Most models only focus on financial markets. However, there exist important spillover effects between real and financial markets. One may try to connect a two-country macroeconomic model with a heterogeneous agent financial market model. This may then also be a promising way to endogenize the fundamental value and let the agents learn the fundamental value from macroeconomic data. Finally, the models are calibrated such that they are able to mimic certain stylized facts. What is needed, however, is a more direct empirical validation of these models, i.e. one should try to estimate the models' structure and parameters with real data.

\section{Conclusions}

The foreign exchange market is characterized by a quite turbulent dynamics. Its market participants are, of course, responsible for this outcome. Guided by empirical evidence, the chartist-fundamentalist approach explores the interactions between heterogeneous speculators. A main finding is that complex foreign exchange dynamics may arise due to the nonlinear interplay between technical and fundamental traders. There exist several natural reasons why this interplay may be nonlinear, in particular (i) trading rules may be nonlinear, (ii) agents may select between trading strategies, or (iii) agents may switch between markets. Buffeted with dynamic noise, models with heterogeneous agents may also match some important stylized facts of financial markets, including uncorrelated price increments, fat tails for the distribution of the returns and volatility clustering. Overall, the chartist-fundamentalist approach may help us understand what is going on in foreign exchange markets and may thus hopefully also be beneficial for designing better trading institutions in the long run. 


\section{References}

Arthur, B., Holland, J., LeBaron, B., Palmer, R. and Tayler, P. (1997): Asset pricing under endogenous expectations in an artificial stock market. In: Arthur, B., Durlauf, S. and Lane, D. (eds): The economy as an evolving complex system II. Addison-Wesley: Reading, 1544.

Bank for International Settlement (2005): Triennial central bank survey of foreign exchange and derivative market activity 2004. BIS: Basle.

Brock, W., Lakonishok, J. and LeBaron, B. (1992): Simple technical trading rules and the stochastic properties of stock returns. Journal of Finance, 67, 1731-1764.

Brock, W. and Hommes, C. (1997): A rational route to randomness. Econometrica, 65, 10591095.

Brock, W. and Hommes, C. (1998): Heterogeneous beliefs and routes to chaos in a simple asset pricing model. Journal of Economic Dynamics Control, 22, 1235-1274.

Caginalp, G., Porter, D. and Smith, V. (2001): Financial bubbles: Excess cash, momentum, and incomplete information. Journal of Psychology and Financial Markets, 2, 80-99.

Chen, S.-H. and Yeh, C-H. (2001): Evolving traders and the business school with genetic programming: A new architecture of the agent-based artificial stock market. Journal of Economic Dynamics and Control, 25, 363-393.

Chiarella, C. (1992): The dynamics of speculative behavior. Annals of Operations Research, 37, 101-123.

Chiarella, C, Dieci, R, and Gardini, L. (2002): Speculative behaviour and complex asset price dynamics: A global analysis. Journal of Economic Behavior and Organization, 49, 173197.

Chiarella, C, Dieci, R, and Gardini, L. (2005): The dynamic interaction of speculation and diversification. Applied Mathematical Finance, 12, 17-52.

Chiarella, C. and He, X.-Z. (2001): Asset price and wealth dynamics under heterogeneous expectations. Quantitative Finance, 1, 509-526.

Chiarella, C. and He, X.-Z. (2005): An asset pricing model with adaptive heterogeneous agents and wealth effects. In : Lux, T., Reitz, S. and Samanidou, E. (eds): Nonlinear Dynamics and Heterogeneous Interacting Agents. Springer: Berlin, 269-285.

Chiarella, C. and Iori, G. (2002): A simulation analysis of the microstructure of the double auction market. Quantitative Finance, 2, 1-8.

Cont, R. (2001): Empirical properties of asset returns: Stylized facts and statistical issues. Quantitative Finance, 1, 223-236.

Day, R. and Huang, W. (1990): Bulls, bears and market sheep. Journal of Economic Behavior and Organization, 14, 299-329.

De Grauwe, P. and Dewachter, H. (1992): Chaos in the Dornbush model of the exchange rate. Kredit und Kapital, 25, 26-54.

De Grauwe, P. and Dewachter, H. (1993): A chaotic model of the exchange rate: The role of fundamentalists and chartists. Open Economies Review, 4, 351-379.

De Grauwe, P., Dewachter, H. and Embrechts, M. (1993): Exchange rate theory - chaotic models of foreign exchange markets. Blackwell: Oxford.

De Grauwe, P. and Grimaldi, M. (2006): Heterogeneity of agents, transactions costs and the exchange rate. Journal of Economic Dynamics and Control, 29, 691-719.

De Grauwe, P. and Grimaldi, M. (2007): Exchange rate puzzles: A tale of switching attractors. European Economic Review, 50, 1-33.

Edwards, R. and Magee, J. (1966): Technical analysis of stock trends. John Magee: Boston.

Farmer, D. (2002): Market force, ecology, and evolution. Industrial and Corporate Change, 
11, 895-953.

Farmer, D. and Joshi, S. (2002): The price dynamics of common trading strategies. Journal of Economic Behavior and Organization, 49, 149-171.

Frankel, J. and Froot, K. (1986): Understanding the U.S. dollar in the eighties: The expectations of chartists and fundamentalists. Economic Record, 62, 24-38.

Frankel, J, and Froot, K. (1987): Using survey data to test standard propositions regarding exchange rate expectations. American Economic Review, 77, 133-153.

Frankel, J. and Froot, K. (1990): Chartists, fundamentalists and the demand for dollars. In: Courakis, A. and Taylor, M. (eds): Private behavior and government policy in interdependent economies. Claendon Press: Oxford, 73-126.

Gandolfo, G. (1985): Economic dynamics: Methods and models. North-Holland: Amsterdam.

Gu, M. (1995): Market mediating behavior: An economic analysis of the security exchange specialists. Journal of Economic Behavior and Organization, 27, 237-256.

Guillaume, D., Dacorogna, M. Dave, R., Müller, U., Olsen, R. and Picet, O. (1997): From the bird's eye to the microscope: A survey of new stylized facts of the intra-daily foreign exchange markets. Finance Stochastics, 1, 95-129.

He, X.-Z. and Westerhoff, F. (2005): Commodity markets, price limiters and speculative price dynamics. Journal of Economic Dynamics and Control, 29, 1577-1596.

Hirshleifer, D. (2001): Investor psychology and asset pricing. Journal of Finance, 56, 15331597.

Hommes, C. (2001): Financial markets as nonlinear adaptive evolutionary systems. Quantitative Finance, 1, 149-167.

Hommes, C., Sonnemans, J., Tuinstra, J. and van de Velden, H. (2005): Coordination of expectations in asset pricing experiments. Review of Financial Studies, 18, 955-980.

Hommes, C. (2006): Heterogeneous agent models in economics and finance. In: Tesfatsion, L. and Judd, K. (eds.): Handbook of computational economics Vol. 2: Agent-based computational economics. North-Holland, Amsterdam.

Huang, W. and Day, R. (1993): Chaotically switching bear and bull markets: The derivation of stock price distributions from behavioral rules. In: Day, R. and Chen, P. (eds.): Nonlinear dynamics and evolutionary economics. Oxford University Press: Oxford, 169182.

Ito, T. (1990): Foreign exchange rate expectations: Micro survey data. American Economic Review, 80, 434-449.

Johnson, N., Jefferies, P. and Hui, P. (2003): Financial market complexity. Oxford University Press: Oxford.

Kahneman, D., Slovic, P. and Tversky, A. (1986): Judgment under uncertainty: Heuristics and biases. Cambridge University Press: Cambridge.

Kaizoji, T. (2002): Speculative price dynamics in a heterogeneous agent model. Nonlinear Dynamics, Psychology and Life Sciences, 6, 217-229.

Kirman, A. (1991): Epidemics of opinion and speculative bubbles in financial markets. In: Taylor, M. (ed.): Money and financial markets. Blackwell: Oxford, 354-368.

Kirman, A. (1993): Ants, rationality, and recruitment. Quarterly Journal of Economics, 108, 137-156.

Lawrenz, C. and Westerhoff, F. (2003): Modeling exchange rate behavior with a genetic algorithm. Computational Economics, 21, 209-229.

LeBaron, B. (1999): Technical trading rule profitability and foreign exchange intervention. Journal of International Economics, 49, 125-143.

LeBaron, B. (2006): Agent-based computational finance. In: Tesfatsion, L. and Judd, K. (eds.): Handbook of computational economics Vol. 2: Agent-based computational 
economics. North-Holland, Amsterdam.

LeBaron, B., Arthur, B. and Palmer, R. (1999): Time Series Properties of an Artificial Stock Market, Journal of Economic Dynamics and Control, 23, 1487-1516.

Li, H. and Rosser , B. (2001): Emergent volatility in asset markets with heterogeneous agents. Discrete Dynamics in Nature and Society, 6, 171-180.

Li, H. and Rosser , B. (2004): Market dynamics and stock price volatility. European Physical Journal B, 39, 409-413.

Lo, A. (2004): The adaptive markets hypothesis: Market efficiency from an evolutionary perspective. Journal of Portfolio Management, 30, 15-29.

Lo, A., Mamaysky, H. and Wang, J. (2000): Foundations of technical analysis: computational algorithms, statistical inference, and empirical implementation. Journal of Finance, 55, 1705-1765.

Lui, Y.-H. and Mole, D. (1998): The use of fundamental and technical analysis by foreign exchange dealers: Hong Kong evidence. Journal of International Money and Finance, 17, $535-545$

Lux, T. (1995): Herd behavior, bubbles and crashes. Economic Journal, 105, 881-896.

Lux, T. (1997): Time variation of second moments from a noise trader/infection model. Journal of Economic Dynamics and Control, 22, 1-38.

Lux, T. (1998): The socio-economic dynamics of speculative markets: Interacting agents, chaos, and the fat tails of return distributions. Journal of Economic Behavior and Organization, 33, 143-165.

Lux, T. (2006): Financial power laws: Empirical evidence, models and mechanisms. In. Cioffi-Revilla, C. (ed.): Power laws in the social sciences: Discovering complexity and non-equilibrium dynamics in the social universe.

Lux, T. and Marchesi, M. (2000): Volatility clustering in financial markets: A microsimulation of interacting agents. International Journal of Theoretical and Applied Finance, 3, 675-702.

Lux, T. and Ausloos, M. (2002): Market fluctuations I: Scaling, multiscaling, and their possible origins. In: Bunde, A., Kropp, J. and Schellnhuber, H. (Eds.): Science of disaster: climate disruptions, heart attacks, and market crashes. Springer: Berlin, 373-410.

Lyons, R. (2001): The microstructure approach to exchange rates. MIT Press: Cambridge.

Mantegna, R. and Stanley, E. (2000): An introduction to econophysics. Cambridge University Press: Cambridge.

Medio, A. (1992): Chaotic dynamics. Cambridge University Press: Cambridge.

Menkhoff, L. (1997): Examining the use of technical currency analysis. International Journal of Finance and Economics, 2, 307-318.

Murphy, J. (1999): Technical analysis of financial markets. New York Institute of Finance: New York.

Palmer, R., Arthur, B., Holland, J., LeBaron, B. and Tayler, P. (1994): Artificial economic life: A simple model of a stock market. Physica D, 75, 264-274.

Pring, M. (1991): Technical analysis explained. McGraw-Hill: New York.

Puu, T. (1989): Nonlinear economic dynamics. Springer: Berlin.

Raberto, M., Cincotti, S., Focardi, S. and Marchesi, M. (2001): Agent-based simulation of a financial market. Phyica A, 299, 319-327.

Rosser, J. B. (2000): From catastrophe to chaos: A general theory of economic discontinuities (second edition). Kluwer Academic Publishers: Boston.

Rosser, B., Ahmed, E. and Hartmann, G. (2003): Volatility via social flaring. Journal of Economic Behavior and Organization, 50, 77-87.

Shiller, R. (2003): From efficient markets theory to behavioral finance. Journal of Economic 
Perspectives, 17, 83-104.

Simon, H. (1955): A behavioral model of rational choice. Quarterly Journal of Economics, 9, 99-118.

Smith, V. (1991): Papers in experimental economics. Cambridge University Press: Cambridge.

Sonnemans, J., Hommes, C., Tuinstra, J. and van de Velden, H. (2004): The instability of a heterogeneous cobweb economy: a strategy experiment on expectation formation. Journal of Economic Behavior and Organization, 54, 453-481.

Sornette, D. (2003): Why stock markets crash. Princeton University Press: Princeton.

Takagi, S. (1991): Exchange rate expectations: A survey of survey studies. IMF Staff Papers, 38, 156-183.

Taylor, M. and Allen, H. (1992): The use of technical analysis in the foreign exchange market. Journal of International Money and Finance, 11, 304-314.

Westerhoff, F. (2003a): Market-maker, inventory control and foreign exchange dynamics. Quantitative Finance, 3, 363-393.

Westerhoff, F. (2003b): Expectations driven distortions in the foreign exchange market. Journal of Economic Behavior and Organization, 51, 389-412.

Westerhoff, F. (2004a): Market depth and price dynamics: A note. International Journal of Modern Physics C, 15, 1005-1012.

Westerhoff, F. (2004b): Multiasset market dynamics. Macroeconomic Dynamics, 8, 596-616.

Westerhoff, F. (2006): Technical analysis and the power of trading breaks. International Journal of Theoretical and Applied Finance, 9, 227-244.

Westerhoff, F. and Reitz, S. (2003): Nonlinearities and cyclical behavior: The role of chartists and fundamentalists. Studies in Nonlinear Dynamics and Econometrics, 7/4, Article 3.

Westerhoff, F. and Wieland, C. (2004): Spillover dynamics of central bank interventions. German Economic Review, 5, 435-450.

Westerhoff, F. and Dieci, R. (2006): The effectiveness of Keynes-Tobin transaction taxes when heterogeneous agents can trade in different markets: A behavioral finance approach. Journal of Economic Dynamics and Control, 30, 293-322. 


\section{LEGENDS FOR FIGURES 1 TO 14}

Figure 1: The dynamics of daily DEM/USD exchange rates from 1974 to 1998 . The panels show from top to bottom the exchange rates, the returns, the probability density function of the returns (the dotted line indicates the normal distribution), the autocorrelation function of raw returns and the autocorrelation function of absolute returns, respectively.

Figure 2: The dynamics of daily JPY/USD exchange rates from 1974 to 1998. The panels show from top to bottom the exchange rates, the returns, the probability density function of the returns (the dotted line indicates the normal distribution), the autocorrelation function of raw returns and the autocorrelation function of absolute returns, respectively.

Figure 3: A linear model. The panels show from top to bottom the log of the exchange rates, the demand of the chartists and the demand of the fundamentalists, respectively.

Figure 4: A nonlinear price impact function. The panels show from top to bottom the log of the exchange rates, the demand of the chartists, the demand of the fundamentalists, and the price adjustment speed, respectively.

Figure 5: A nonlinear fundamental trading rule. The panels show from top to bottom the $\log$ of the exchange rates, the demand of the chartists and the demand of the fundamentalists, respectively.

Figure 6: A simple variation of the previous model. The panels show from top to bottom the log of the exchange rates, the demand of the chartists and the demand of the fundamentalists, respectively.

Figure 7: A different nonlinear fundamental trading rule. The panels show from top to bottom the log of the exchange rates, the demand of the chartists and the demand of the fundamentalists, respectively.

Figure 8: Selection of trading rules depending on misalignment. The panels show from top to bottom the log of the exchange rates, the demand of the chartists, the demand of the fundamentalists, and the fraction of chartists, respectively.

Figure 9: A simple variation of the previous model. The panels show from top to bottom the log of the exchange rates, the demand of the chartists, the demand of the fundamentalists, and the fraction of chartists, respectively.

Figure 10: Selection of trading rules depending on past fitness. The panels show from top to bottom the log of the exchange rates, the demand of the chartists, the demand of the fundamentalists, and the fraction of chartists, respectively.

Figure 11: Interactions between markets. The panels show from top to bottom the log of the exchange rates in market 1 , the log of the exchange rates in market 2 , and the log of the cross rates between markets 1 and 2, respectively.

Figure 12: The dynamics in phase space. The log of the exchange rate of period $t$ is plotted against the log of the exchange rate in period $t-1$ for the eight nonlinear models of section 4 .

Figure 13: The dynamics of a simple stochastic herding model. The panels show from top to bottom the fraction of chartists, the log of the exchange rates, the returns, the probability density function of the returns, the autocorrelation function of raw returns and the autocorrelation function of absolute returns, respectively. 

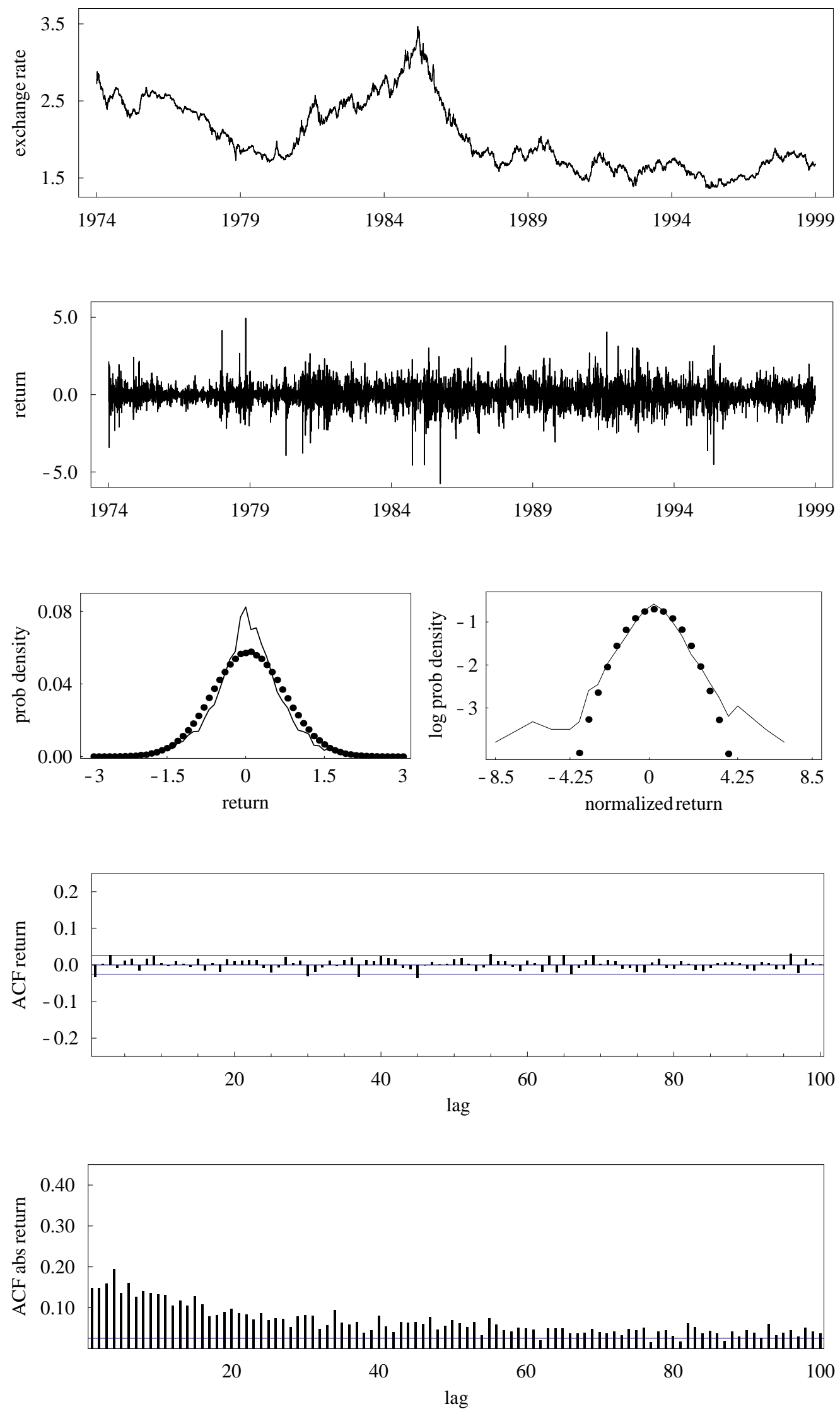

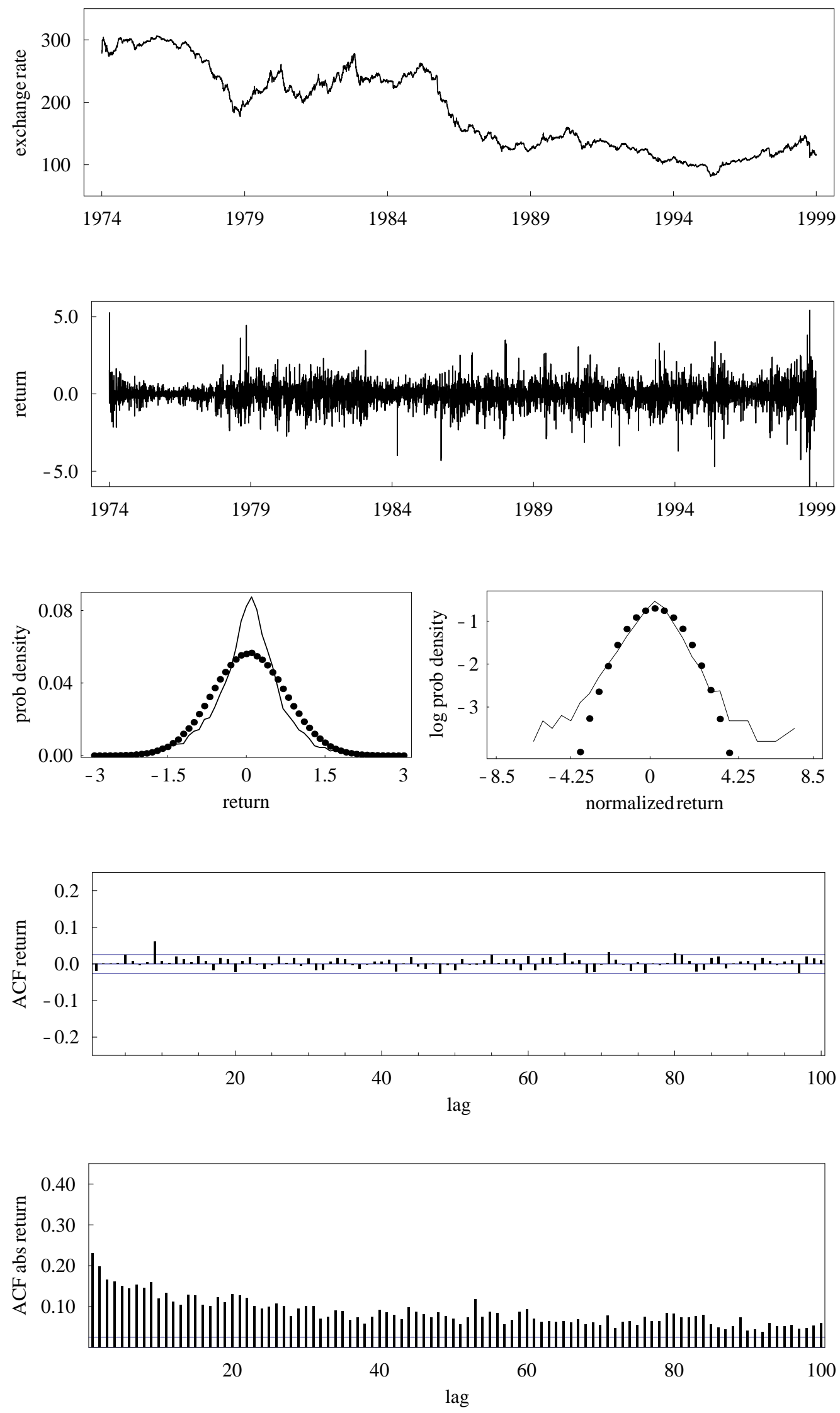

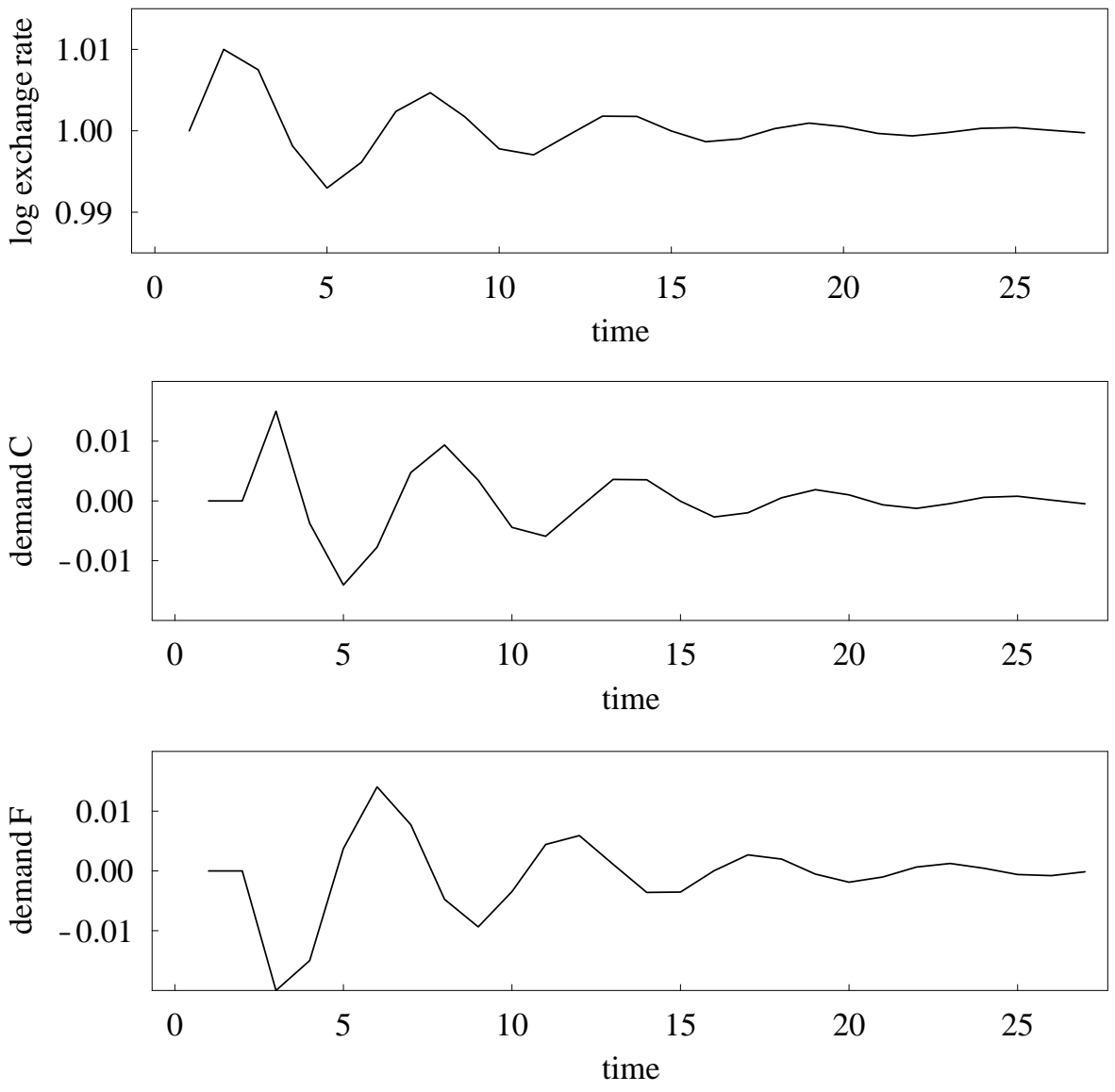

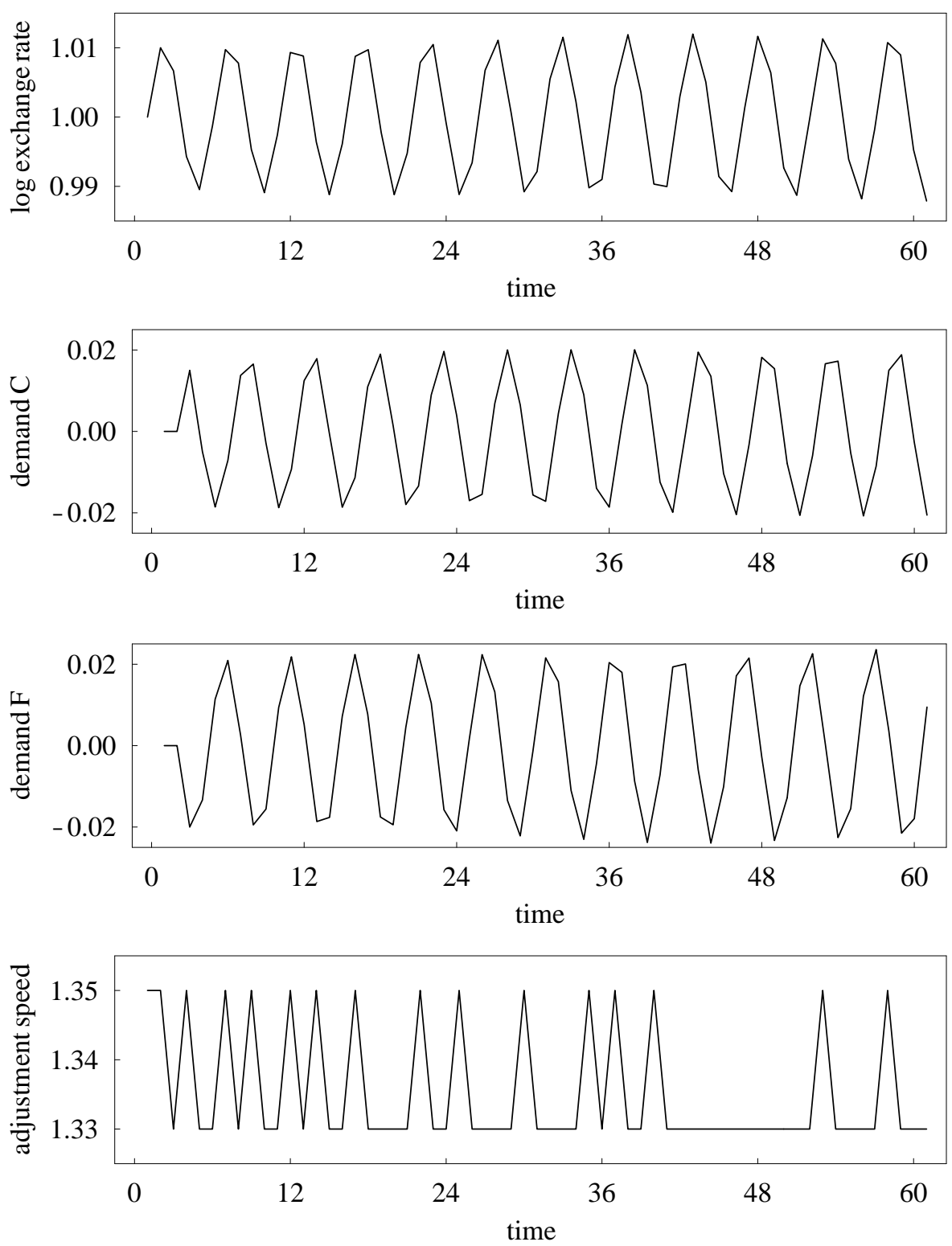

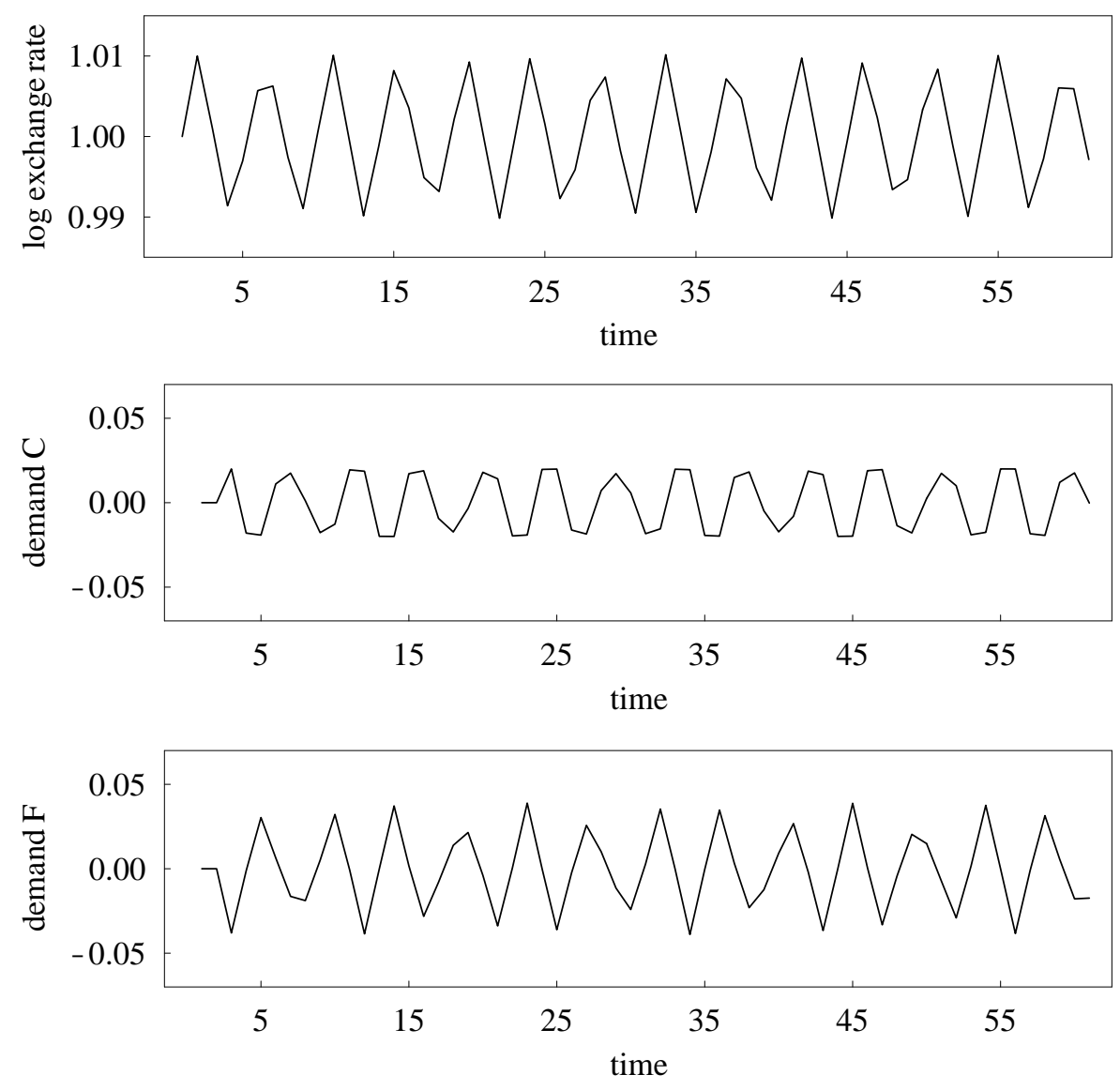

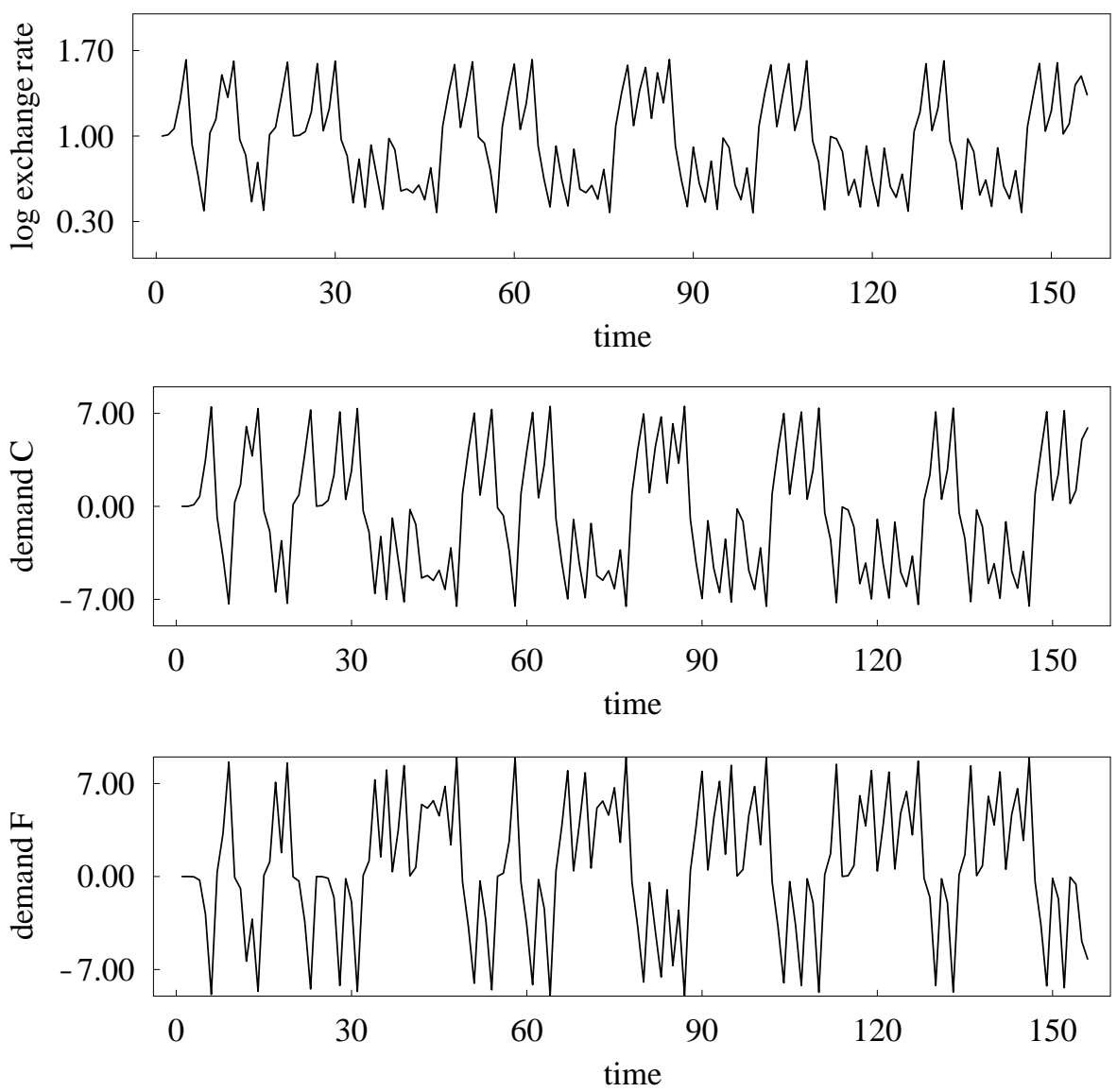

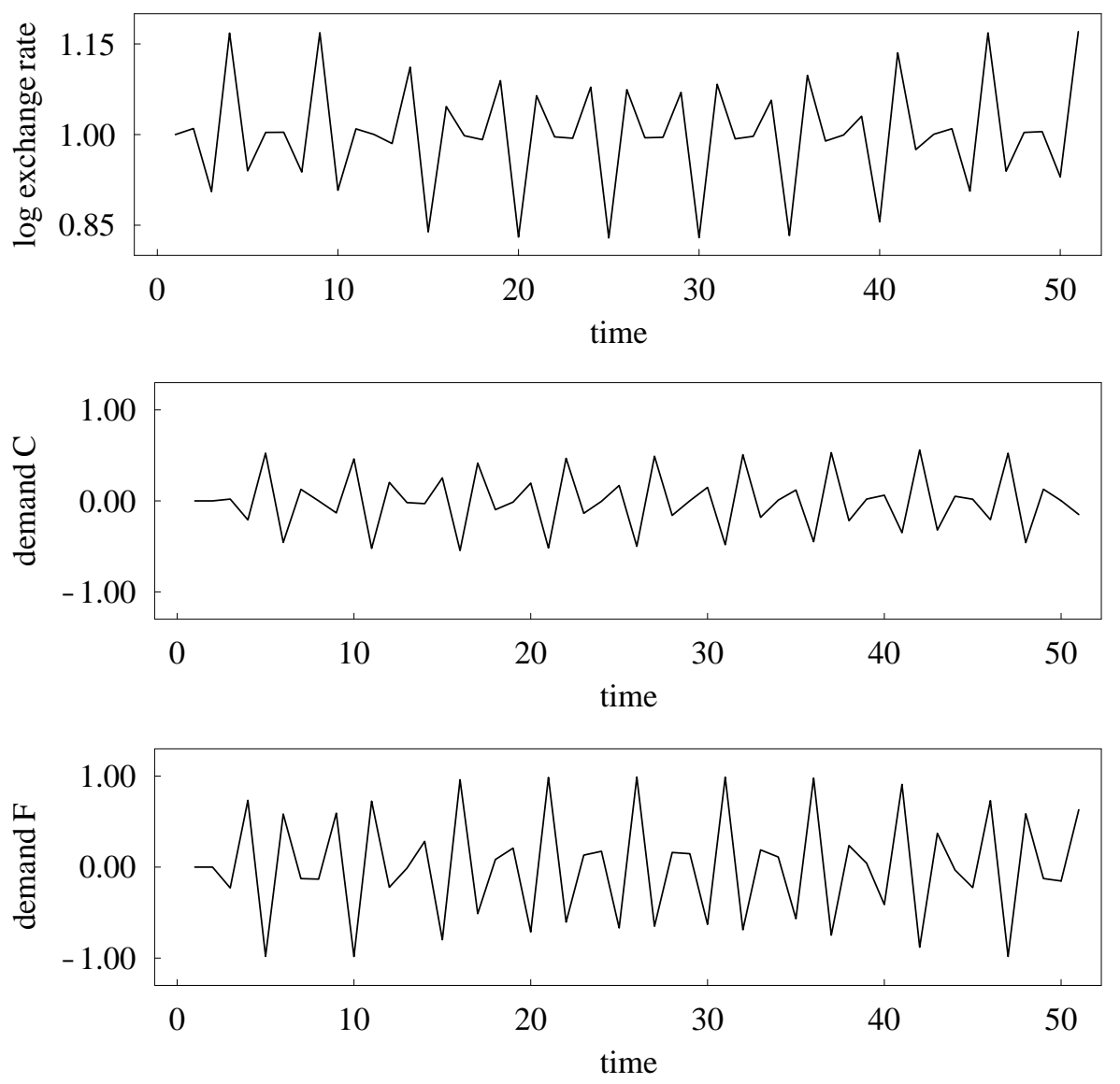

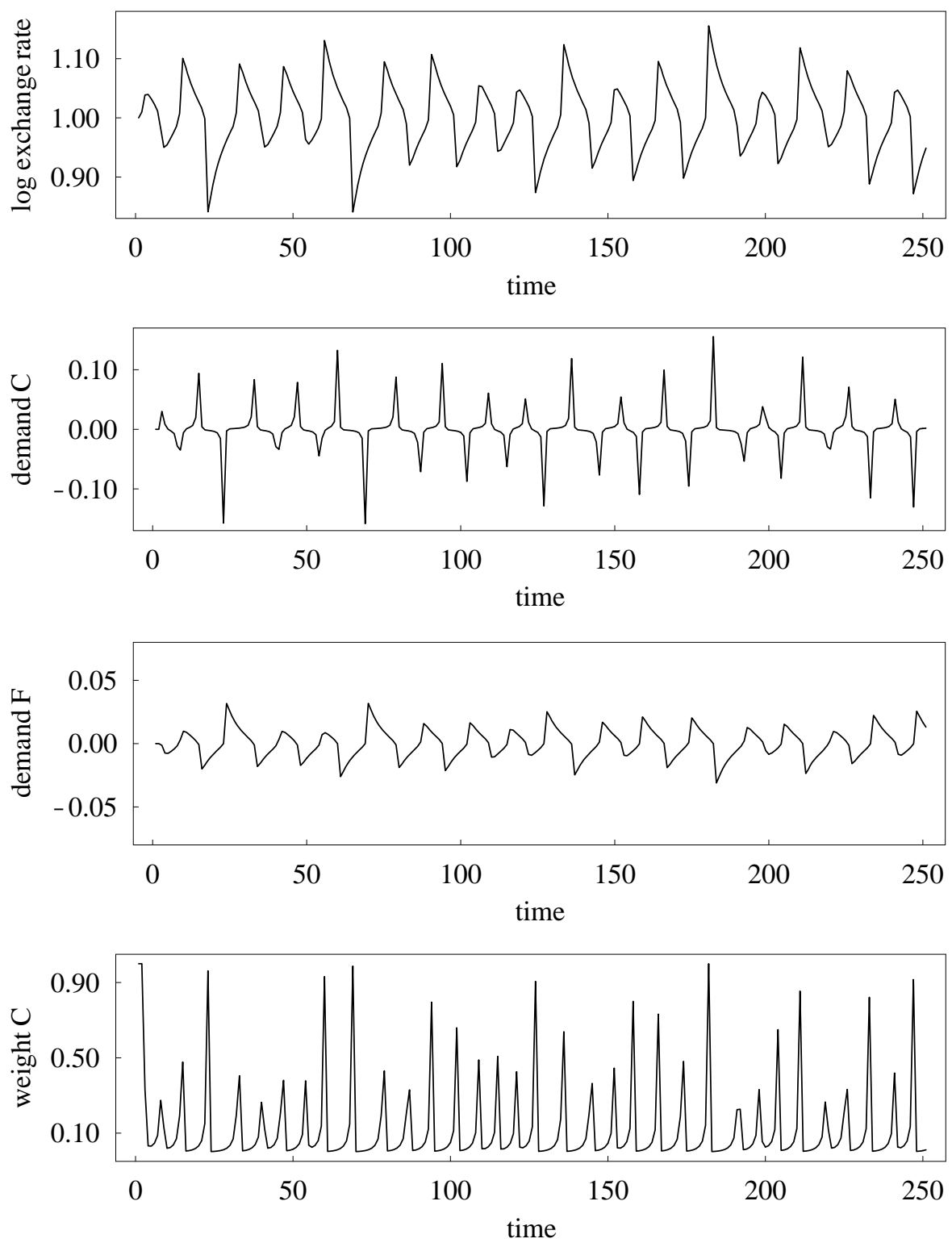

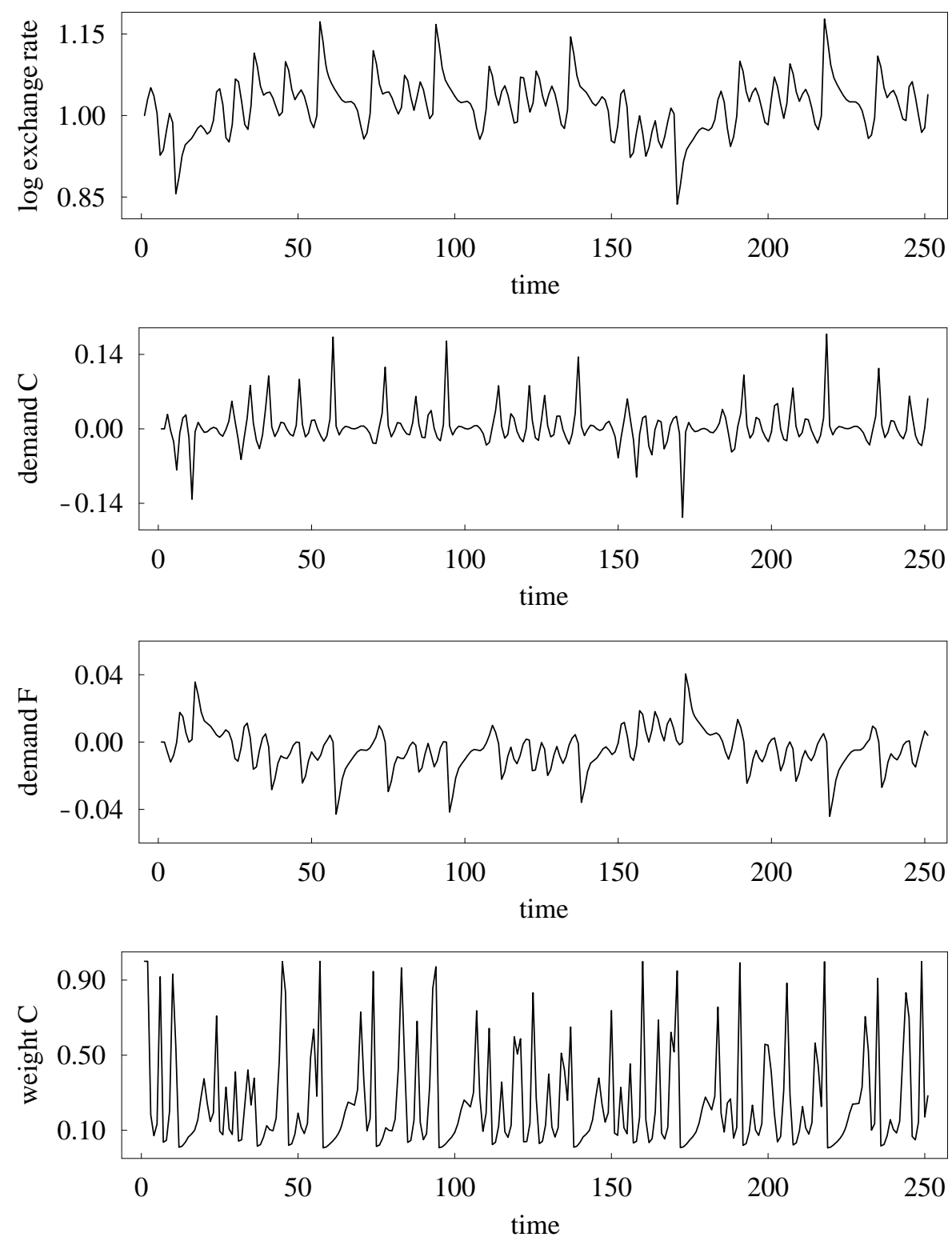

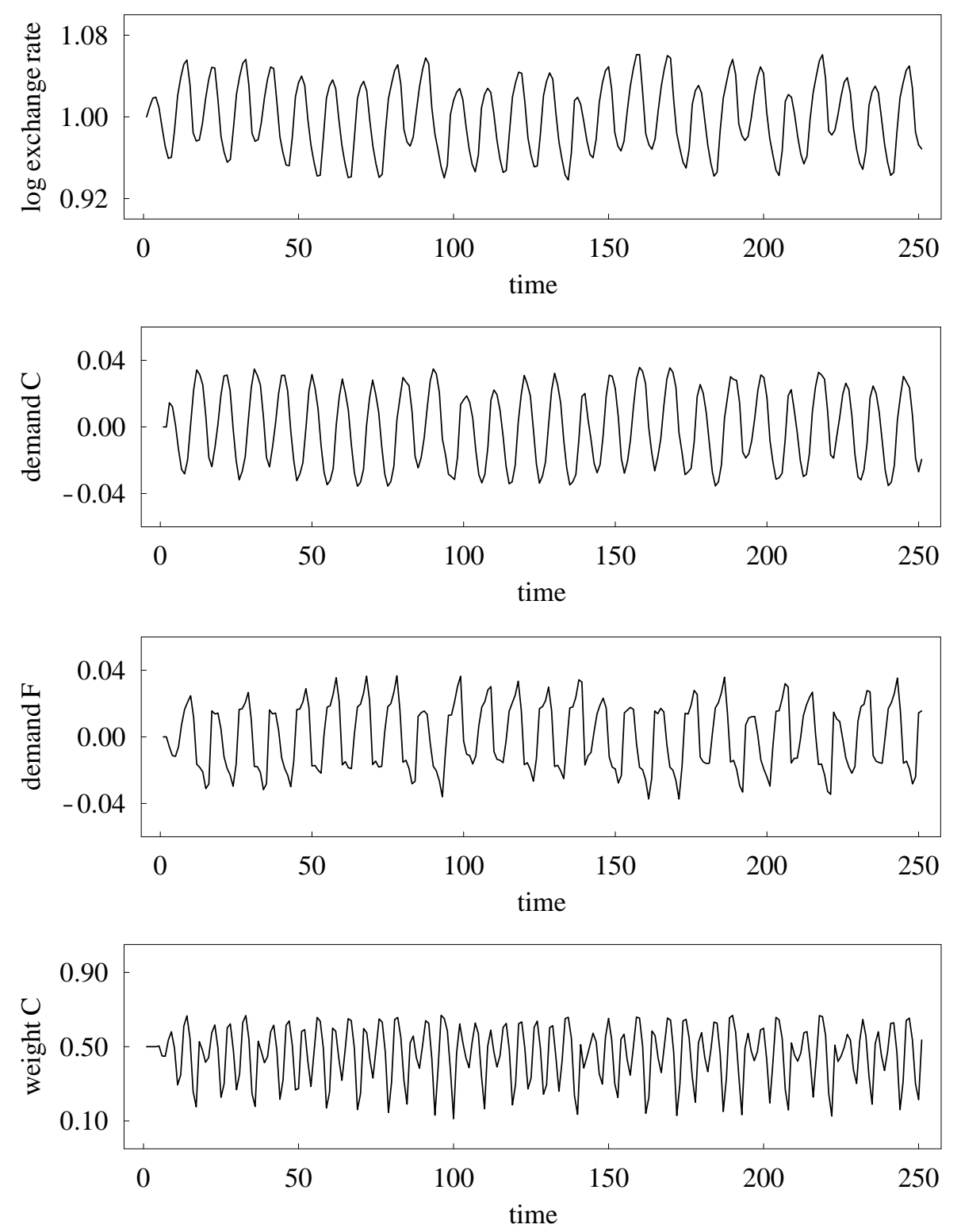

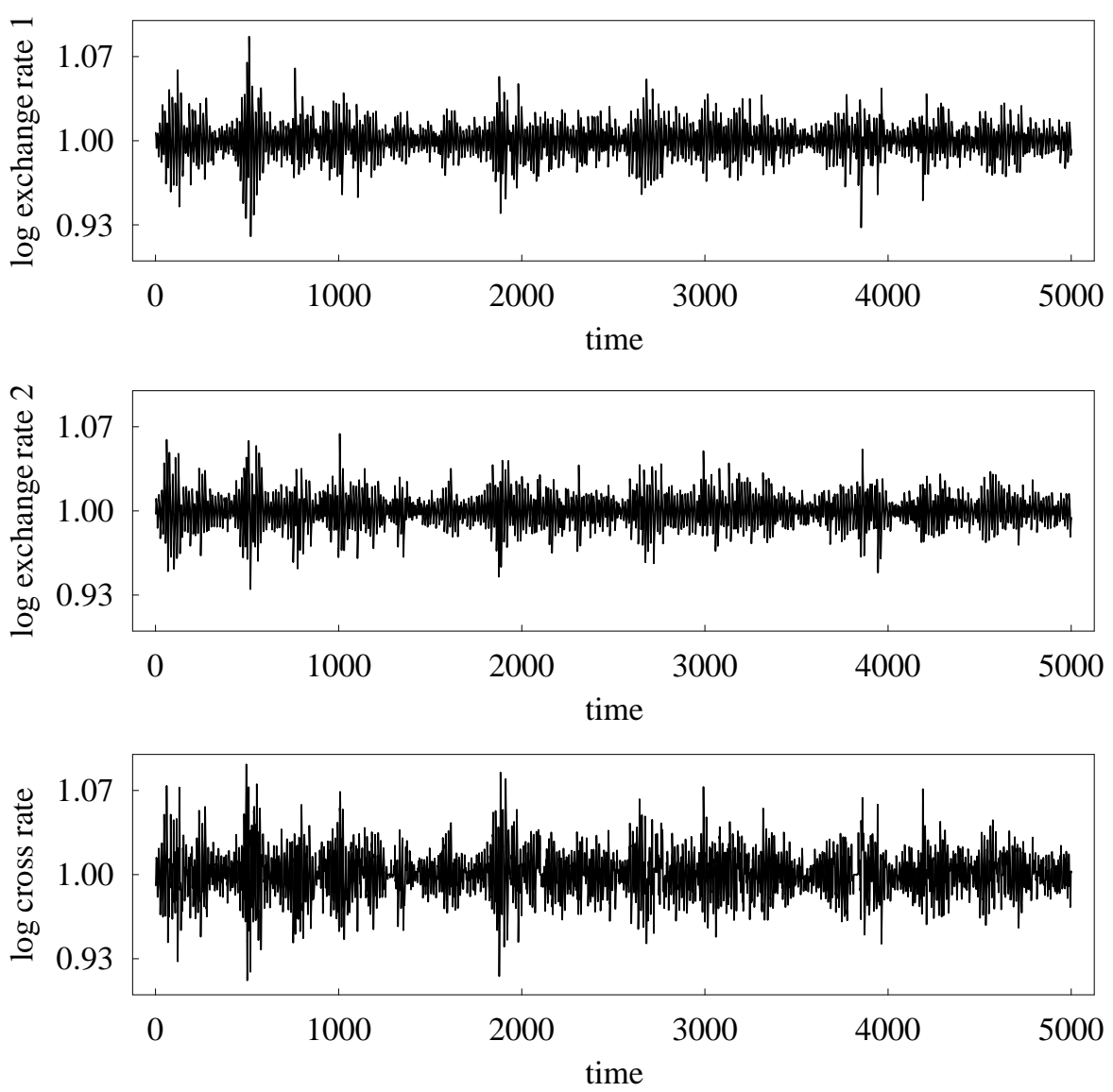


$$
\begin{aligned}
& 8 \\
& 8 x \\
& +1
\end{aligned}
$$



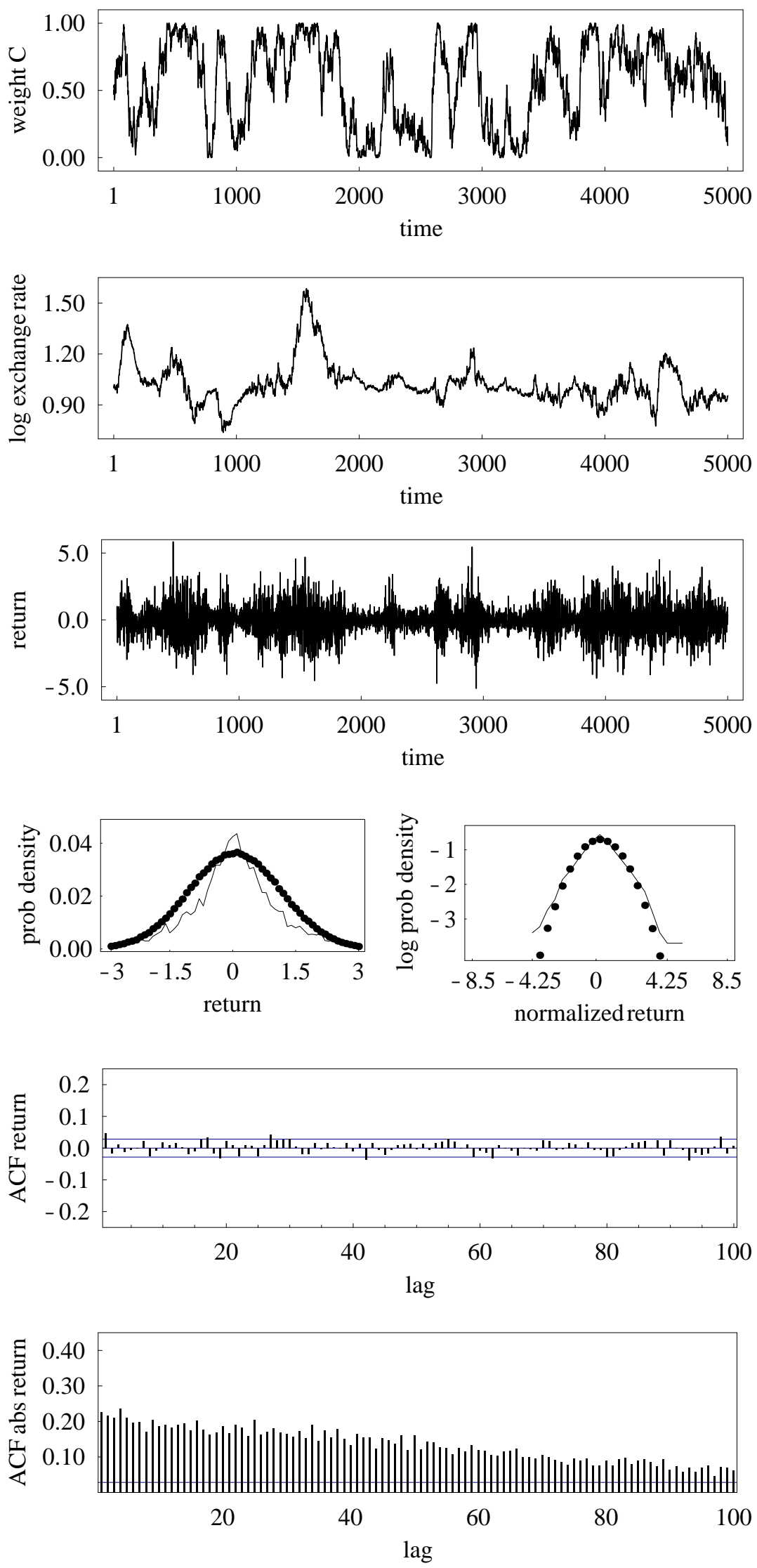